\title{
Experimental characterisation and numerical modelling of the influence of bondline thickness, loading rate, and deformation mode on the response of adhesive interfaces
}

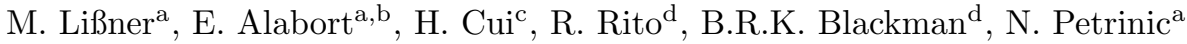 \\ ${ }^{a}$ Department of Engineering Science, University of Oxford, Parks Road, Oxford, OX1 3PJ, United Kingdom \\ ${ }^{b}$ OxMet Technologies Ltd., 34 Centre for Innovation and Enterprise, Begbroke Science Park, Begbroke, OX5 1PF, \\ United Kingdom \\ ${ }^{c}$ School of Aerospace, Transport and Manufacturing, Cranfield University, Bedford, MK43 0AL, United Kingdom \\ ${ }^{d}$ Department of Mechanical Engineering, Imperial College, South Kensington Campus, London, SW7 2AZ, United \\ Kingdom
}

\begin{abstract}
A new method for characterising the rate-dependent failure of elasto-plastic adhesively bonded structures has been developed and used to investigate the different modes of loading of representative interfaces. Furthermore, experimental observations enabled a newly developed cohesive zone model that captures all critical aspects of the observed and quantified behaviour of the adhesive under consideration. In particular, the model is capable of reproducing the conducted experiments by incorporating both the dependence of the deformation rate and the adhesive thickness. For that, computed tomography of the adhesive interface was used to resolve three-dimensionally the adhesive volume. The volume fraction of microscopic voids in the adhesive was introduced into the model to rationalise the observed dependence of the mechanical response of the adhesive upon its thickness. Finally, the cohesive zone model was proven with mixed-mode fracture experiments which demonstrate the model's ability to simulate more complex deformation regimes.
\end{abstract}

Keywords: adhesive joints, dynamic loading, cohesive zone modelling, experimental mechanics

\section{Introduction}

Adhesive joints are becoming critically important for the automotive and aerospace industries [1, 2] as they enable the production of lightweight structures which seamlessly combine metallic alloys with polymer matrix composites. The adhesive joining method offers substantial advantages over traditional joining techniques such as mechanical fastening; particularly, stress concentrating holes can be avoided and a more homogeneous stress distribution can be achieved [3]. Many 
researchers have investigated adhesive joints in terms of (i) their mechanical performance in quasistatic loading regimes [3, 4, 5, 6, 7, 8, (ii) their dependency on the interface thickness [9, 10, 11, 12] and (iii) their fracture toughness [13, 14, 15, 16, 17, 18, 19] by considering the pioneering work of [20, 21. However, relatively few studies have been reported on the understanding of adhesive joints under dynamic loading conditions [22, 23, 24, 25, 26, 27]; potentially due to a lack of standardisation and to the difficulty of separating dynamic effects such as inertia or oscillation from the actual behaviour [28, 29, 30, 31]. It is, therefore, critically important to develop new and adapt existing methodologies that can provide reliable measurements of the behaviour, including fracture process in particular, of adhesively-bonded structures subjected to a wide range of loading rates.

Moreover, reliable experimental characterisation of the adhesive interface is the foundation for development of mathematical models for predictive simulation of the performance of adhesives at larger length scales. Since the adhesive layer is relatively thin compared to the global structure, the cohesive zone model approach (CZM) [32, 33, 34] offers a practical and scalable modelling solution. However, the accuracy of these models heavily rely upon the precise determination of thus defined properties of adhesive interfaces [35. The CZM is capable of modelling damage initiation and propagation to failure in a single analysis. A traction-separation law (TSL) is required to represent the mechanical behaviour of the adhesive layer - this relates the traction stress of the adhesive interface to the separation displacement. Because the thickness of the adhesive is very small when compared to its width, it is reasonable to assume plane strain conditions. This simplifies the process and allows direct application of the CZM. However, care is advised when one studies thick hyperelastic joints. A significant number of studies have been carried out to predict failure of adhesive joints with various different shapes of the TSL: bilinear, exponential and trapezoidal amongst others [36, 37. - most of them independent of the loading rate and/or the adhesive thickness. There is experimental evidence [38] that the stress and the dissipated energy are dependent on the loading rate. With this in mind, models capable of representing rate-dependent material behaviour, have already been developed [39, 40, 41, 36, 42. However, most of them do not take into consideration the influence of the adhesive layer thickness, thus calling for the incorporation of observed thicknessdependent features into the modelling approaches. A unified model which explicitly includes the size effect of the interface has practical advantages and is proposed and discussed here.

The aim of the present work is to develop both a unified experimental and modelling framework that allows direct measurement of the behaviour under any rate of interest and that considers any 
effect introduced by the size of the interface. For this, a mathematical model which represents the rate- and thickness-dependent behaviour of adhesive interfaces is presented and calibrated. First, the behaviour of adhesive joints with different thicknesses is investigated under mode I, mode II, and mixed-mode fracture. Second, the three-dimensional volume of the interface is resolved using computed tomography, thus allowing precise information of the internal flaws present in the adhesive to be addressed. Third, a traction-separation law which builds upon existing mathematical models for adhesive interfaces is proposed. This adds the appropriate dependence of the thickness and the rate on the strength and the fracture path. Finally, the developed model is implemented into a finite element modelling framework and is proven with the mixed-mode experimentation.

\section{Experimental methods}

The rate-dependent characterisation of adhesive interfaces requires an experimental method suitable for quasi-static up to highly dynamic loading regimes. This involves the identification of an optimal specimen design which is appropriate for different loading modes and which can be used in the Split Hopkinson bar. It is relevant to note that in this paper, we adopt fracture mechanics nomenclature to define the different loading modes - mode I, mode II and mixed-mode. However, these refer to equivalent continuum mechanics experiments employed to directly extract information required when working with the CZM approach. As opposed to traditional fracture mechanic experiments (such as ENF, SLB and DCB), the experiments carried out here do not have a defined crack tip. These types of experiments and the procedure to acquire and measure experimental data are explained in this section. Moreover, the nature and type of adhesive is also detailed.

\subsection{Experimental setup, specimen design and adhesive material}

The scope of this work was to develop a unified experimental methodology which is valid under any loading regime to enable a direct interpretation of the effect of deformation rates. Thus, the specimen geometries of each loading mode had to be designed with high-rate experimentation in mind - specimens were designed with specific geometries that match the mechanical impedance between loading bars and end caps. Specimen geometries for each loading mode are shown in Figure 1. These consist of: (i) a butt-joint with $4 \mathrm{~mm}$ thick end caps for mode I; (ii) a single-lap shear specimen with an overlap length of $10 \mathrm{~mm}$ for mode II; and (iii) a $45^{\circ}$ angled surface for 
mixed-mode. The end-caps were manufactured using the titanium alloy $\mathrm{Ti}-6 \mathrm{Al}-4 \mathrm{~V}$ which is the same material employed in the loading bars. For the adhesive, the thermosetting epoxy film adhesive AF 163-2OST was used. This adhesive is a rubber toughened epoxy and it is supported with a glass fibre carrier matte and was provided by $3 \mathrm{M}$ Scotch-Weld ${ }^{T M}$. Three bondline thicknesses of $0.1,0.3$ and $0.5 \mathrm{~mm}$ have been manufactured to determine the influence of the interface thickness on the mechanical behaviour of the joint.

An optimal adhesive joint requires appropriate surface treatments prior bonding. In the present study, the surfaces of the titanium end caps were grit-blasted, etched, and anodised following the procedure described in [43]. The bonding fixture illustrated in Figure 2(a) was used to accurately manufacture mode I specimens with the specified thicknesses - similar fixtures were manufactured for mode II and mixed-mode specimens. After manufacturing, the bondline was measured. Measurements are reported in Figure2 (b) - these have an error below 3\%.

The high-rate (HR) experiments were performed on a Split Hopkinson Tensile Bar (SHTB) apparatus [44, particular details are provided in [45]. The specimens were loaded with a velocity of $v=3000 \mathrm{~mm} / \mathrm{s}$. The quasi-static (QS) and medium-rate (MR) experiments were carried out using high-stiffness screw-driven servo-electric and servo-hydraulic testing machines respectively. For QS, a velocity of $v=0.05 \mathrm{~mm} / \mathrm{s}$ was applied; for MR, a velocity of $v=10 \mathrm{~mm} / \mathrm{s}$ was employed. To measure displacements, digital image correlation (DIC) was employed. For HR, one ultra-highspeed camera was used to capture the whole test. In MR and QS, two cameras were employed: the ultra-high-speed camera was employed to measure the rapid separation of the adhesive joint during fracture and a second standard camera was used to capture the separation displacement during the loading step. For HR, the resulting force was measured using the attached strain gauges on the loading bars. For MR and QS, the loading force was measured using the load cell from the testing frame while the rapid unloading process was measured using a strain gauge attached to the loading bar. The force was then synchronised with the displacement following the procedure previously described by the authors [45].

\subsection{Microstructural characterisation}

It is well established that the voids present in the bulk adhesive will have an effect on the mechanical performance of the joint. In order to assess the quantity, shape and size of these voids or pores, X-ray computer tomography (XCT) was used to obtain a detailed representation 
of the adhesive microstructure for each one of the thicknesses of interest and for each loading mode. X-ray scans with a resolution of $836 \times 863 \times 272$ voxels were taken (each voxel represented $12.44 \times 12.44 \times 12.44 \mu \mathrm{m})$. A volume of $10.40 \times 10.74 \times 3.38 \mathrm{~mm}$ was measured. To estimate the void volume fraction, the scans were transformed in gray-scale images and reconstructed using the postprocessing software Amira. This allowed the measurement of each void independently. The volume fraction of voids was calculated following

$$
f_{\mathrm{v}}=\frac{V_{\mathrm{v}}}{V}
$$

where $V_{\mathrm{v}}$ is the total volume taken by the voids while $V$ is the total volume of the adhesive when assuming that no voids are present. Small errors are expected associated with the resolution of the $\mathrm{XCT}$ scan and the threshold employed to identify the voids.

For the identification of the fractured surface, a scanning electron microscope (SEM) was employed. The samples were gold coated prior to fractographic analysis to generate a conductive surface. Representative specimens were chosen to microscopically determine the nature of the fractured surface. Additionally, a 3D optical microscope was used to measure the three-dimensional profile of the fractured surface - this provides important information about the interface failure type i.e. proportions of cohesive failure vs. adhesion failure present.

\section{Experimental Results}

In this section, the experimental results for each one of the loading modes, thicknesses and loading rates are shown. Then, the results are analysed to identify how each of those factors affect the peak traction and the dissipated energy. Additionally, the adhesive's microstructure is investigated before experimentation via computed tomography - this measures the presence of defects which might influence the mechanical performance of the bonded structure. Finally, the fractured surfaces of the adhesive joint are microscopically investigated to identify the type of failure.

\subsection{Experimental traction-separation curves}

Characterisation experiments have been performed at laboratory temperature to investigate the mechanical performance of adhesive joints as a function of: (i) the loading rate, (ii) the loading 
mode, and (iii) the interface thickness. Recorded force and displacement conditions were processed to obtain the nominal tensile traction stress and tensile separation displacement curves for each condition. Traction-separation curves are summarised in Figure 3.

First, results suggest that the initial elastic response of specimens for the loading modes I and mixed-mode are strain-rate independent. Mode II results suggest a slight strain-rate-dependent behaviour. All loading modes show a trapezoidal shaped curve independent of the adhesive thickness and the loading rate. The mean maximum traction is highly dependent on the strain-rate for all the loading modes - between QS and $\mathrm{HR}$, it increases from $40 \mathrm{MPa}$ to $60 \mathrm{MPa}$ under mode I, from $35 \mathrm{MPa}$ to $50 \mathrm{MPa}$ under mode II, and from $38 \mathrm{MPa}$ to $55 \mathrm{MPa}$ under mixed-mode fracture. Moreover, the mean peak stress is shown to be independent of the adhesive thickness independently of loading rate for both mode I and mode II fracture. Additionally, the mean maximum traction for loading mode II is around $4 \mathrm{MPa}$ lower than the mode I mean maximum traction. For mixed-mode fracture the mean maximum traction shows a decrease with increasing adhesive thickness.

Second, Figure 3 results also show that the final failure displacement increases with increasing adhesive thickness - up to a certain value where the maximum final failure displacement stops increasing. For QS, this displacement threshold is approximately $0.25 \mathrm{~mm}$ for mode I, $0.55 \mathrm{~mm}$ for mode II and $0.3 \mathrm{~mm}$ for mixed-mode. For HR, this displacement threshold is approximately 0.07 $\mathrm{mm}$ for mode I, $0.15 \mathrm{~mm}$ in mode II and $0.1 \mathrm{~mm}$ in mixed-mode - a substantial decrease when compared to the QS values. Indeed, the final failure displacement decreases with increasing strain rate. Consequently, the dissipated energy (area under the whole traction-separation curve) has a negative rate dependency for all investigated loading modes - i.e. it decreases with increasing strain rate, especially for mode II where it is approximately double than that reported for mode I.

\subsection{On the mode-, rate- and thickness-dependent behaviour}

Experimental results suggest that the peak stress for the loading mode I and mode II increases with increasing loading rate. The dissipated energy and the plateau ratio show decrease as the loading rate increases this is more evident in mode II and mixed-mode - see Figure 4 This observation is in agreement with several investigations found in literature where the fracture energy also decreased with increasing strain rate 28. However, it is also worth mentioning that other adhesives have shown an increase of the critical strain energy release rate with increasing loading rate [36, 42]. The peak stress and the dissipated energy are believed to be rate-dependent due to the 
polymeric nature of the adhesive. One might expect that the mechanical performance of the adhesive is heavily based on the independent behaviour of the molecular chains of the polymeric matrix. The entangled molecule chains are reorientating themselves depending on the direction of the applied load. A rapid deformation would lead to the inability of the chains to adjust themselves in time to the applied load. This results in the observed higher resistance and lower failure displacement in the dynamic loading regime. On the contrary, if the molecular chains are subjected to a slower applied load, the time to reorientate is higher. Then, their full mechanical properties are utilized until the maximum performance is reached [46].

Figure 5 compares the dissipated energy measured via continuum mechanical to the fracture mechanical experiments performed by Alvarez et. al. [47. This study employed the same adhesive than the current study but with a different thickness. Thus, experimental results for adhesive thicknesses of $t_{\mathrm{a}}=0.3$ and $0.5 \mathrm{~mm}$ are compared to literature results which employ a thickness of $0.4 \mathrm{~mm}$. The dissipated energy obtained with the continuum mechanical experiments is in reasonable agreement with the literature fracture mechanical experiments - similar loading mode dependence is observed.

\subsection{X-ray tomography of voids and their effect on adhesion}

Figure 6 confirms and illustrates the initial presence of voids and pores inside each one of the investigated adhesives using X-ray tomography. The void volume fraction was calculated using the Amira's statistical measurement tools which allow to determine the total volume of the voids inside the adhesive layer. The distribution of pore size was estimated by calculating an equivalent void diameter based on a sphere geometry - see Figure 6. It is shown that the void size distribution is similar for each one of the thicknesses. Moreover, the void size distribution in Figure 6 illustrates that rubber particles of the adhesive have not been considered since they have a diameter below 1 $\mu \mathrm{m}$. The employed CT method does not have enough resolution to resolve such small particles or defects. Additionally, Figure 6 demonstrates that the thickest adhesive layer $\left(t_{\mathrm{a}}=0.5 \mathrm{~mm}\right)$ has a larger number of voids than the thinner adhesives but the volume fraction of voids is smaller than 0.3 and $0.1 \mathrm{~mm}$ thicknesses.

The void volume fraction of pores $f_{\mathrm{v}}$ for each loading mode is $f_{\mathrm{v}}=5.9 \%\left(t_{\mathrm{a}}=0.1 \mathrm{~mm}\right), 3.1$ $\%\left(t_{\mathrm{a}}=0.3 \mathrm{~mm}\right)$ and $3.0 \%\left(t_{\mathrm{a}}=0.5 \mathrm{~mm}\right)$ for mode $\mathrm{I}, f_{\mathrm{v}}=8.8 \%\left(t_{\mathrm{a}}=0.1 \mathrm{~mm}\right)$, and $3.3 \%\left(t_{\mathrm{a}}\right.$ $=0.5 \mathrm{~mm})$ for mode II and $f_{\mathrm{v}}=5.1 \%\left(t_{\mathrm{a}}=0.1 \mathrm{~mm}\right)$, and $3.5 \%\left(t_{\mathrm{a}}=0.5 \mathrm{~mm}\right)$ for mixed-mode. 
Considering that the void volume fraction is independent of the loading mode an error ranging from 1.1 to $2.6 \%$ is obtained. This confirms that a RVE is not achieved: the thinner the adhesive, the larger the volume fraction of voids. Moreover, X-ray tomography shows that, for the thinnest bondline, some of the larger pores cover the whole adhesive thickness. This explains some of the results shown in Figure 35 abnormally low values of dissipated energy were measured for $t_{\mathrm{a}}=0.1$ $\mathrm{mm}$. The following general observations can be drawn: (i) the employed adhesive is rich of voids, (ii) the number of voids increases with increasing adhesive layer thickness, (iii) the void distribution is similar throughout for each of the measured thicknesses and (iv) the void volume fraction decreases with larger adhesive thickness following a power law distribution - see Figure 6(3). This behaviour can be expressed as

$$
f_{v}\left(t_{a}\right)=f_{v r e f} \cdot t_{a}^{-f_{v 0}}
$$

where $f_{\text {vref }}$ is the reference value and $f_{v 0}$ is the thickness sensitivity parameter. The relationship and its values are provided in Figure6(3).

It is believed that the void volume fraction is related to the adhesive thickness due to the manufacturing process of the specimens and the number and size of pores presented in the initial film adhesive. When manufacturing the thicker adhesives, several layers of $0.2 \mathrm{~mm}$ films are compressed together. This allows for more adhesive material to compress and collapse voids, therefore reducing the effective volume fraction of voids at larger thicknesses. For the thinnest adhesive layers, because the size of some pores present in the initial film are similar in size to the actual adhesive layer, pore occlusion is difficult and the volume fraction of voids in the manufactured component is higher.

\subsection{On the nature of fracture}

Figure 7 shows the fractured surfaces of mode I and II samples with a thickness of $0.1 \mathrm{~mm}$. The form of the voids in the fractured samples suggests that these existed before deformation. In normal direction (mode I), the voids keep a spherical form - a mostly normal load will break the voids in half, but these will keep their round shape. In the case of shear loading, the observed elliptical shape suggests that these where deformed as a consequence of large shear strains.

Figure 8 compares the effect of rate and loading mode for a thickness of $0.5 \mathrm{~mm}$. An abundance of voids (4) on the surface fracture is evident. This confirms the CT measurements. Voids are evenly distributed - this is expected to have a major effect on the fracture performance of the

adhesive. Moreover, a typical adhesive failure - as opposed to cohesion failure - is observed. More 
particular details of the different fracture phenomena are highlighted and detailed as follows: As a result of the applied force, the supporting fibres debond from the matrix (1) and result either in fibre pull-out (3) or in fibre fracture (2). Moreover, matrix failure (5) is predominant independently of loading mode. Furthermore, hackles (6) and cusps (7) are observed. These are common shear fracture characteristics and are most predominant under mode II fracture. Additionally, it can be assumed that the majority of the energy dissipation is due to the action of the rubber particles, causing cavitation of the epoxy matrix, void growth and shear yielding of the matrix between the particles.

Optical micrographs of the whole fracture surface for each one of the loading modes and thicknesses are shown in Figure 9 for; (a) medium-rate and different thicknesses/modes; and (ii) a thickness of $0.3 \mathrm{~mm}$ and different modes/rates. Images show that cohesive failure is predominant. Three-dimensional profile measurements of the surfaces show that the fracture line is mostly within the thickness range of each one of the studied adhesive interfaces, thus proving that cohesive failure occurred. This approves the use the CZM approach.

\section{Modelling methods}

The aim of this section is to provide a unified model of the adhesive interface where the influence of the rate and the thickness are explicitly embedded into the constitutive equations. The goal is to propose a model which is faithful to the observed phenomena and which is flexible and suitable for large structural stress analyses which employ finite element methods. For this reason, the cohesive zone model approach is employed. The mathematical description of the model is tailored to the observed phenomena.

\subsection{A modified cohesive zone model}

The aim of this work is to provide a unified model of the adhesive interface where the influence of the rate and the thickness are explicitly embedded into the constitutive equations. The goal is to propose a model which is faithful to the observed phenomena and which is flexible and suitable for large structural stress analyses which employ finite element methods. For this reason, the cohesive zone model approach is employed. The mathematical description of the model was modified to better suit the expected phenomena and was later calibrated employing the experimentally obtained 
data in the form of force-displacement curves for mode I and II loading. The model was then proven using mixed-mode results.

The proposed mathematical model is motivated by the approach presented by Marzi et. al. 42, where a trilinear CZM represents the irreversible deformation which occurs at the adhesive interface when cracks nucleate and propagate. This model will be referred as the baseline model for comparison. Figure 10(a) presents a typical TSL with a trilinear shape. This constitutive model is here modified to better capture the observed experimental phenomena. In order to demonstrate the advantages of this model, both the baseline and the modified models are calibrated and compared to the experimental results. Figure 10(b) illustrates the rheological differences between the modified TSL and the baseline TSL as described in [42] and it shows the employed energy terminology. The resultant energy of the TSL is divided in two parts: (i) a plateau energy, which is believed to represent possible plastic deformation, crack nucleation, crack propagation and crack coalescence, and (ii) the whole area under the curve, that represents the dissipated energy. Particular details of the proposed mathematical model are explained in the following subsections.

\subsection{Rate-dependent formulation of peak stress, dissipated energy and plateau area}

The CZM is intended to be applicable in industrial sectors where no extremely stiff adherents are used. Therefore, it is reasonable to assume that any rate-dependent behaviour of the high adhesive stiffness - observed in Figure 3 - is negligible for the mechanical behaviour of the bonded structure. Therefore, this model neglects the rate-dependent behaviour of the stiffness. On the other hand, key mechanical parameters such as the peak stress or the dissipated energy can be made rate-dependent by employing exponential or logarithmic expressions which are a function of the strain rate. In the present study, three mechanical parameters have been identified as rate-dependent: the peak stress, the dissipated energy and the plateau energy. Experimentation suggests that the peak stress follows a logarithmic relationship. For mode $\mathrm{I}$, the maximum traction $T_{\mathrm{N}}$ is expressed as:

$$
T_{\mathrm{N}}\left(\dot{\varepsilon}_{\mathrm{N}}\right)=T_{\mathrm{refN}}+T_{0 \mathrm{~N}} \cdot \ln \left(\frac{\dot{\varepsilon}_{\mathrm{N}}}{\dot{\varepsilon}_{\mathrm{ref}}}\right)
$$

while for mode II, the maximum traction $T_{\mathrm{S}}$ is expressed as:

$$
T_{\mathrm{S}}\left(\dot{\varepsilon}_{\mathrm{S}}\right)=T_{\mathrm{refS}}+T_{0 \mathrm{~S}} \cdot \ln \left(\frac{\dot{\varepsilon}_{\mathrm{S}}}{\dot{\varepsilon}_{\mathrm{ref}}}\right)
$$


where $T_{\text {refN }}, T_{\text {refS }}$ and $T_{0 \mathrm{~N}}, T_{0 \mathrm{~S}}$ are the reference values of peak stress and the strain rate sensitivity parameters respectively. The parameter $\dot{\varepsilon}_{\text {ref }}$ is the reference strain rate, and $\dot{\varepsilon}_{\mathrm{i}}$ is the strain rate which is expressed following

$$
\dot{\varepsilon}_{\mathrm{i}}=\frac{v}{t_{a}} \text { with } i=N, S
$$

where $v$ is the applied velocity, $t_{a}$ the adhesive thickness and $i=N, S$ represents the strain rate in normal and tangential direction respectively.

The dissipated energy is also a logarithmic function of the strain rate. The mode I dissipated energy $G_{\mathrm{cN}}$ is described as

$$
G_{\mathrm{cN}}\left(\dot{\varepsilon}_{\mathrm{N}}\right)=G_{\mathrm{refN}}-G_{0 \mathrm{~N}} \cdot \ln \left(\frac{\dot{\varepsilon}_{\mathrm{N}}}{\dot{\varepsilon}_{\mathrm{ref}}}\right)
$$

while the mode II dissipated energy $G_{\mathrm{CS}}$ is described as:

$$
G_{\mathrm{cS}}\left(\dot{\varepsilon}_{\mathrm{S}}\right)=G_{\mathrm{refS}}-G_{0 \mathrm{~S}} \cdot \ln \left(\frac{\dot{\varepsilon}_{\mathrm{S}}}{\dot{\varepsilon}_{\mathrm{ref}}}\right)
$$

where $G_{\text {refN }}$ and $G_{\text {refS }}$ are the reference values of the dissipated energy in mode I and mode II respectively, and $G_{0 \mathrm{~N}}$ and $G_{0 \mathrm{~S}}$ represent the strain rate sensitivity parameters for each mode.

In the present model, the plateau area is also rate-dependent - this is represented by the ratio between the plateau energy and the dissipated energy according to:

$$
P_{N}\left(\dot{\varepsilon}_{\mathrm{N}}\right)=P_{\text {refN }} \cdot\left(\frac{\dot{\varepsilon}_{\mathrm{N}}}{\dot{\varepsilon}_{\text {ref }}}\right)^{p_{\mathrm{N}}}
$$

and

$$
P_{S}\left(\dot{\varepsilon}_{\mathrm{S}}\right)=P_{\mathrm{refS}} \cdot\left(\frac{\dot{\varepsilon}_{\mathrm{S}}}{\dot{\varepsilon}_{\mathrm{ref}}}\right)^{p_{\mathrm{S}}}
$$

where $P_{\text {refN }}$ and $P_{\text {refS }}$ are the reference values for mode I and mode II respectively, and $p_{\mathrm{N}}$ and $p_{\mathrm{S}}$ are the strain rate sensitivity parameters of the plateau ratio.

\subsection{Influence of adhesive thickness and void volume fraction on peak stress and dissipated energy}

Both the peak stress and the dissipated energy are here considered to be influenced by the initial void volume fraction obtained from XCT scans. However, $f_{\mathrm{v}}$ it is not treated as a damage variable, therefore, it will not increase over time. For simplicity, it is assumed that any damage occurring 
after the initial state is considered inside the damage variable $d$. Additionally, experimental results suggest an influence of the adhesive thickness on the dissipated energy - see Figure 4 Due to the very thin adhesive interfaces, it is believed that no representative volume can be obtained for all three investigated layer thicknesses. Therefore, Eqs 3, 4, 6, 7 are modified to account for the changes in maximum traction and dissipated energy that voids will introduce following

$$
T_{\mathrm{N}}\left(\dot{\varepsilon}_{\mathrm{N}}, f_{\mathrm{v}}\right)=\left[T_{\mathrm{refN}}+T_{0 \mathrm{~N}} \cdot \ln \left(\frac{\dot{\varepsilon}_{\mathrm{N}}}{\dot{\varepsilon}_{\text {ref }}}\right)\right] \cdot\left(1-f_{\mathrm{v}}\right)
$$

and

$$
T_{\mathrm{S}}\left(\dot{\varepsilon}_{\mathrm{S}}, f_{\mathrm{v}}\right)=\left[T_{\mathrm{refS}}+T_{0 \mathrm{~S}} \cdot \ln \left(\frac{\dot{\varepsilon}_{\mathrm{S}}}{\dot{\varepsilon}_{\mathrm{ref}}}\right)\right] \cdot\left(1-f_{\mathrm{v}}\right)
$$

for the peak stress in mode I and mode II respectively. The dissipated energy is then expressed as

$$
G_{c N}\left(\dot{\varepsilon}_{\mathrm{N}}, f_{\mathrm{v}}\right)=\left[G_{\mathrm{refN}}-G_{0 \mathrm{~N}} \cdot \ln \left(\frac{\dot{\varepsilon}_{\mathrm{N}}}{\dot{\varepsilon}_{\mathrm{ref}}}\right)\right] \cdot\left(1-f_{\mathrm{v}}\right) \cdot\left(t_{r e f}-\frac{t_{0}}{t_{a}}\right)
$$

and

$$
G_{C S}\left(\dot{\varepsilon}_{\mathrm{S}}, f_{\mathrm{v}}\right)=\left[G_{\mathrm{refS}}-G_{0 \mathrm{~S}} \cdot \ln \left(\frac{\dot{\varepsilon}_{\mathrm{S}}}{\dot{\varepsilon}_{\mathrm{ref}}}\right)\right] \cdot\left(1-f_{\mathrm{v}}\right) \cdot\left(t_{r e f}-\frac{t_{0}}{t_{a}}\right)
$$

for mode I and mode II respectively. Here, it is assumed that the dissipated energy is reduced proportionally to the reduction in volume induced by voids - see $\left(1-f_{\mathrm{v}}\right)$. Moreover, experiments show a great dependence between dissipated energy and adhesive thickness. This dependence is considered in a phenomenological manner by the expression $\left(t_{r e f}-\frac{t_{0}}{t_{a}}\right)$, where $t_{r e f}$ and $t_{0}$ are the reference value for the thickness and the thickness sensitivity parameter respectively.

\subsection{Traction-separation law}

A traction-separation law assumes that there is a damage evolution process taking place that effectively degrades the stiffness of the material. This damage is typically expressed as a scalar damage variable $d$. The traction components of the material after damage onset can be described using

$$
t=(1-d) \cdot K \cdot \delta
$$

where $t$ is the traction, $\delta$ the separation value and $K$ is the stiffness of the structure. Figure 10 shows the representation of a tri-linear CZM for different modes of fracture. It should be noted 
that the strain rate is updated until the yield initiation limit $\delta_{\mathrm{m}}>\delta_{\mathrm{m} 1}$ is reached. Hence, the TSL is dependent on the equivalent strain rate at yield initiation [42]. The maximum traction and the yield initiation of the material which includes the influence of mode I and mode II, are defined with a quadratic criterion which can be written in displacement terms following

$$
\left(\frac{\delta_{\mathrm{m} 1, \mathrm{I}}}{\delta_{\mathrm{n} 1}}\right)^{2}+\left(\frac{\delta_{\mathrm{m} 1, \mathrm{II}}}{\delta_{\mathrm{s} 1}}\right)^{2}=1
$$

where the yield initiation $\delta_{\mathrm{m} 1}$ can be calculated using the expression

$$
\delta_{\mathrm{m} 1}=\delta_{\mathrm{n} 1} \cdot \delta_{\mathrm{s} 1} \sqrt{\frac{1+\beta^{2}}{\delta_{\mathrm{n} 1}^{2}+\left(\delta_{\mathrm{s} 1} \cdot \beta\right)^{2}}}
$$

considering an equivalent mixed-mode displacement

$$
\delta_{\mathrm{m} 1}=\sqrt{\delta_{\mathrm{m} 1, \mathrm{I}}^{2}+\delta_{\mathrm{m} 1, \mathrm{II}}^{2}}
$$

and a mixed-mode ratio with

$$
\beta=\frac{\delta_{\mathrm{m} 1, \mathrm{II}}}{\delta_{\mathrm{m} 1, \mathrm{I}}} .
$$

The yield initiation displacement is then fully described with the relevant displacements for each mode separately. This is described following

$$
\delta_{\mathrm{n} 1}=\frac{T_{\mathrm{N}}}{K_{\mathrm{n}}} \quad \text { and } \quad \delta_{\mathrm{s} 1}=\frac{\mathrm{T}_{\mathrm{S}}}{\mathrm{K}_{\mathrm{s}}}
$$

where the indices $n$ and $s$ represent mode I and mode II respectively. The stiffness for each mode is calculated considering plane strain conditions following

$$
K_{\mathrm{n}}=\frac{E}{t_{\mathrm{el}}} \quad \text { and } \quad \mathrm{K}_{\mathrm{s}}=\frac{\mathrm{G}}{\mathrm{t}_{\mathrm{el}}}
$$

where $E$ is the Young's modulus (2000 MPa), $G$ the shear modulus (440 MPa), and $t_{\mathrm{el}}$ is the element thickness as a user-defined value. Analogously, a linear criterion in the form of

$$
\left(\frac{\delta_{\mathrm{mi}, \mathrm{I}}}{\delta_{\mathrm{ni}}}\right)+\left(\frac{\delta_{\mathrm{mi}, I \mathrm{II}}}{\delta_{\mathrm{si}}}\right)=1 \quad i=2, f
$$


is used to obtain the damage initiation $\delta_{\mathrm{m} 2}$ and the final failure displacement $\delta_{\mathrm{mf}}$ with the expression

$$
\delta_{\mathrm{mi}}=\delta_{\mathrm{ni}} \cdot \delta_{\mathrm{si}} \frac{\sqrt{1+\beta^{2}}}{\left(\beta \delta_{\mathrm{ni}}+\delta_{\mathrm{si}}\right)} \quad i=2, f .
$$

The relevant mode I and II dependent components for the damage initiation are described by

$$
\delta_{n 2}=\delta_{n 1}+\frac{2 \cdot G_{c N} \cdot P_{N}}{T_{\mathrm{N}} \cdot\left(1+\gamma_{N}\right)} \quad \text { and } \quad \delta_{s 2}=\delta_{s 1}+\frac{2 \cdot G_{c S} \cdot P_{N}}{T_{\mathrm{S}} \cdot\left(1+\gamma_{S}\right)}
$$

whereas the mode I and II components for the final failure displacement are expressed as

$$
\delta_{n f}=\delta_{n 1}+\delta_{n 2}+\frac{2 \cdot G_{c N}}{T_{\mathrm{N}} \cdot \gamma_{N}}-\frac{\delta_{n 2}+\gamma_{N} \cdot\left(\delta_{n 2}-\delta_{n 1}\right)}{\gamma_{N}}
$$

and

$$
\delta_{s f}=\delta_{s 1}+\delta_{s 2}+\frac{2 \cdot G_{c S}}{T_{\mathrm{S}} \cdot \gamma_{S}}-\frac{\delta_{s 2}+\gamma_{S} \cdot\left(\delta_{s 2}-\delta_{s 1}\right)}{\gamma_{S}}
$$

where the parameters $\gamma_{N}$ and $\gamma_{S}$ enable the representation of a softening plateau area. These parameters represent a fraction of the maximum traction.

Then, the damage $d$ can be fully defined as

$$
d=\left\{\begin{array}{cc}
0 & , \delta \leq \delta_{\mathrm{m} 1} \\
1-\frac{\delta_{m 1}}{\delta_{m}} \cdot\left[1+\frac{\left(\gamma_{m}-1\right)\left(\delta_{m}-\delta_{m 1}\right)}{\left(\delta_{m 2}-\delta_{m 1}\right)}\right] & , \delta_{\mathrm{m} 1}<\delta \leq \delta_{\mathrm{m} 2} \\
1-\left[\frac{\gamma_{m} \cdot \delta_{m 1}}{\delta_{m}} \cdot \frac{\left(\delta_{m f}-\delta_{m}\right)}{\left(\delta_{m f}-\delta_{m 2}\right)}\right] \cdot\left[2 \cdot\left(\frac{\delta-\delta_{\mathrm{m} 2}}{\delta_{\mathrm{mf}}-\delta_{\mathrm{m} 2}}\right)^{3}-3 \cdot\left(\frac{\delta-\delta_{\mathrm{m} 2}}{\delta_{\mathrm{mf}}-\delta_{\mathrm{m} 2}}\right)^{2}+1\right] & , \delta_{\mathrm{m} 2}<\delta \leq \delta_{\mathrm{mf}} \\
1 & , \delta>\delta_{f}
\end{array}\right.
$$

where $\gamma_{m}$ represents the percentage of plateau decrease for the mixed mode case and that follows

$$
\gamma_{\mathrm{m}}=\sqrt{\frac{\gamma_{\mathrm{N}}^{2}+\left(\beta \cdot \gamma_{\mathrm{S}}\right)^{2}}{\left(1+\beta^{2}\right)}} .
$$

Consequently, the traction-separation relationship following Eq14 is fully described by considering that the stiffness $K$ of the structure also includes the influence of mode I and mode II employing

$$
K=\sqrt{\frac{K_{\mathrm{n}}^{2}+\left(\beta \cdot K_{\mathrm{s}}\right)^{2}}{\left(1+\beta^{2}\right)}} .
$$




\section{Modelling Results}

In this section, the proposed CZM is calibrated with the experimental results. For this, mode I and mode II numerical results are employed. The fitness of the model is then assessed and compared with the baseline CZM. Finally, the flexibility and accuracy of the model is proven via simulation of the mixed-mode experiments.

\subsection{Determination of rate and thickness dependent parameters for CZM}

Before the proposed CZM model can be used, the values of the material parameters need to be determined. In order to simplify and avoid overuse of material constants, a step-by-step optimisation process was followed - where the mechanical characteristics of the traction-separation law were extracted and identified separately from experiments. This is also used to compare the advantages of the modified TSL over the baseline model. The optimisation procedure is illustrated in Figure 11.

Firstly, the void volume fraction $f_{\mathrm{v}}$ is measured for the loading modes I, II and mixed-mode for each adhesive thickness. The experimental results in Section 3 suggest a power law distribution of the void volume fraction with increasing adhesive thickness as it is expressed in Eq2.

Secondly, the parameters related to the peak stresses for mode I and mode II are identified - see Figure 12. It is observed that the maximum traction values for mode I and mode II are different. Thus, one needs to employ mode-dependent parameters. The result of the modified TSL Eq. 10 and 11 are shown as blue lines for each thickness independently. The effect of imperfections such as voids in the initial structure is introduced via effective values of stresses which depend on the volume fraction of voids. The baseline TSL parameters are also fitted to the experiments for comparison purposes: these are represented with black solid lines. For both modes, the modified model is capable of representing better the experimental results - due to the introduction of the void volume fraction. For the baseline model, a compromise between the different thicknesses had to be found - this negatively influences the overall fitness of the model. Table 1 shows the identified values which represent the rate-dependent behaviour of the maximum stress for modes I and II.

Third, the parameters that relate the sensitivity of the dissipated energy to the strain rate and the adhesive thickness are determined. The dissipated energy for both loading modes shows a linear decrease with increasing strain rate. Figure 13 shows that the modified model formulation is able to capture the linear decrease. With the baseline TSL, a decreasing exponential behaviour is 
Table 1: Rate-dependent parameters for the maximum traction.

\begin{tabular}{c|cc}
\hline \multirow{2}{*}{ Mode I } & $T_{\text {refN }}(\mathrm{MPa})$ & $T_{0 \mathrm{~N}}$ \\
\cline { 2 - 3 } & 38.00 & 1.90 \\
\hline \multirow{2}{*}{ Mode II } & $T_{\text {refS }}(\mathrm{MPa})$ & $T_{0 \mathrm{~S}}$ \\
\cline { 2 - 3 } & 35.00 & 1.80 \\
\hline
\end{tabular}

achieved. However, this formulation results in a similar dissipated energy for MR and HR results. This negatively influences the overall fitness of the model to the experimental results. Furthermore, the values $t_{r e f}=1.13$ and $t_{0}=0.05$ describe the thickness dependence of the dissipated energy which is shown by Figure 14 Table 2 shows the identified values which represent the rate-dependent behaviour of the dissipated energy for modes I and II.

Fourth, parameters related to the shape and size of the plateau are identified. As shown in Figure 15, it is evident that the plateau area decreases as the strain rate increases. Moreover, the plateau area is smaller in mode I than in mode II. To capture this, the modified TSL introduces an exponential dependence between the plateau ratio and the strain rate - see Equations 8 and 9 The slight decrease in the plateau area, especially evident for mode II, is considered by defining $\gamma_{\mathrm{N}}=1$ and $\gamma_{\mathrm{S}}=0.85$. In the case of the baseline TSL, the plateau ratio is constant. Comparison between both show the improved fitness of our approach. Table 3 shows the identified values which represent the rate-dependent behaviour of the plastic plateau for modes I and II.

When comparing side-by-side the modified and the baseline models, the following is observed: (i) the rate dependency of peak stress can be represented by both models - but the modified TSL takes into account the effect of voids; (ii) the dissipated energy shows an improvement with the modified model over the baseline TSL for the present adhesive due to the change in the strain-rate sensitivity relationship and to the introduction of the void volume fraction and adhesive thickness dependence; and (iii) the rate-dependent formulation of the plastic plateau allows one to capture strain-rate effects - while the baseline is insensitive to those.

Figure 16 shows the calculated traction-separation curves after calibration of the material parameters. Computed curves are compared to the experimental results shown as shaded areas. The graphs show that the model is able to capture the rate and thickness dependency of the adhesive joint. A good agreement of the traction-separation behaviour and the experimental results is shown. However, the model does not provide an accurate representation of the high-rate response 
Table 2: Rate and thickness dependent parameters for the dissipated energy.

\begin{tabular}{c|cc}
\hline \multirow{2}{*}{ Mode I } & $G_{\text {refN }}\left(\frac{N}{m m}\right)$ & $G_{0 \mathrm{~N}}$ \\
\cline { 2 - 3 } & 5.00 & 0.25 \\
\hline \multirow{2}{*}{ Mode II } & $G_{\mathrm{refS}}\left(\frac{\mathrm{N}}{\mathrm{mm}}\right)$ & $G_{0 \mathrm{~S}}$ \\
\cline { 2 - 3 } & 11.50 & 0.23 \\
\hline
\end{tabular}

Table 3: Rate-dependent parameters for the plateau ratio.

\begin{tabular}{c|cc}
\hline \multirow{2}{*}{ Mode I } & $P_{\text {refN }}$ & $p_{\mathrm{N}}$ \\
\cline { 2 - 3 } & 0.65 & -0.01 \\
\hline \multirow{2}{*}{ Mode II } & $P_{\text {refS }}$ & $p_{\mathrm{S}}$ \\
\cline { 2 - 3 } & 0.80 & -0.03 \\
\hline
\end{tabular}

under mode I. Substantial deviation is also observed on the elastic response of pure mode II for the thinnest adhesive layer. It is believed that this is due to a size effect induced by the voids when the adhesive layer is minimal.

\subsection{CZM validation: mixed-mode comparison}

To demonstrate the suitability of the model, mixed-mode experiments - which were not considered during the parameter determination step are used to assess the interpolation capability of the model under different loading directions. In order to assure that the same mix of normal and tangential displacement is applied in the simulations, the displacement in both normal and shear directions are extracted from the experimental images. These displacements are then applied as boundary conditions in each one of the adherents of the mixed-mode simulations. This procedure is illustrated in Figure 17. By considering the exact experimental boundary conditions, displacement fluctuations during the experiments are considered. The extracted displacement histories for the different loading regimes and adhesive thicknesses are summarised in Figure 18. These show that the perpendicular to loading direction displacements $(\mathrm{x})$ are small compared to the loading direction displacements (y).

Figure 19 represents the model results as solid lines whereas the experiments are shown as shaded areas. Overall, the model provides a good representation of the mixed-mode behaviour of the adhesive. However, for the thinnest bondline the model deviates more noticeably than for other thicknesses. Particularly regarding the displacement behaviour observed at the highest and at the 
lowest loading rate. Similar observations were reported for mode I results in Figure 16 For an adhesive thickness of $0.3 \mathrm{~mm}$ the model represents the observed behaviour of the adhesive interfaces very well, while for the thickness of $0.5 \mathrm{~mm}$ the deviation between model and experiment increases.

The developed model serves as a good representation of experiments with mixed-mode behaviour. Therefore, it is fair to conclude that the presented model can be used to model complex bonded structures. Because the traction-separation law was defined as a function of the bond thickness (this is a state variable), the model may be used to simulate the performance of bonded structures with local differences on the thickness of the bonding interface. Moreover, due to the unified nature of the constitutive law, the same model can be applied over a wide range of loading rates and loading modes. Finally, the model includes the effect of initial porosity on the performance of the adhesive interface which has been proved experimentally to have an important effect on the mechanical ability of the interface.

\section{Conclusions}

The following conclusions can be drawn from this work:

1. The mechanical response of a titanium-titanium alloy bond using the film adhesive AF 1632OST has been characterised using uniaxial tensile testing. Experiments reveal a significant dependence on the deformation rate, the adhesive interface thickness, and the mode of loading.

2. Microstructural assessment and computed tomography describe the initial presence of voids in the adhesive. These are proved to negatively influence the mechanical performance of the bond. Void volume fraction measurements at different thicknesses demonstrate the absence of a representative volume element. Their influence on the fracture process is confirmed with post-mortem fractography.

3. 3D fractography measurements prove the existence of cohesive failure at all loading rates and thicknesses for each loading mode experimented. This observation allows one to employ cohesive zone models to represent adhesive performance.

4. A cohesive zone model that describes the observed constitutive response of the adhesive interface in form of a traction separation law is formulated. The model is usable over the whole range of deformation rates and loading modes experimented. Moreover, the model includes the effect of the bondline thickness and porosity on mechanical performance. 
5. The flexibility of the unified experimental and modelling framework is proven by performing mixed-mode experiments. This framework offers a simple and versatile tool to measure and model adhesives. The modified cohesive zone model shows its suitability to predict the behaviour of adhesive bond structures under various loading modes, loading rates, and bondline thicknesses.

\section{Acknowledgements}

The authors of this paper are grateful to Dr. Borja Erice, Norwegian University of Science and Technology, and to Prof Clive Siviour, University of Oxford, for their support and suggestions. The authors are grateful to Jeffrey Fullerton and Stuart Carter, Impact Engineering Laboratory, University of Oxford, for their assistance in manufacturing the specimens. The authors acknowledge the funding from Rolls-Royce plc which enabled this investigation. 


\section{References}

[1] M. D. Banea, L. F. M. da Silva, Adhesively bonded joints in composite materials: an overview, Journal of Materials Design and Applications 223 (1) (2009) 1-18. doi:10.1243/14644207

[2] N. Badwe, R. Mahajan, K. Sieradzki, Interfacial fracture strength and toughness of copper / epoxy-resin interfaces, Acta Materialia 103 (2016) 512-518. doi:10.1016/j.actamat.2015. 10.009 .

URL http://dx.doi.org/10.1016/j .actamat.2015.10.009

[3] B. R. K. Blackman, A. J. Kinloch, F. S. Rodriguez Sanchez, W. S. Teo, J. G. Williams, The fracture behaviour of structural adhesives under high rates of testing, Engineering Fracture Mechanics 76 (18) (2009) 2868-2889. doi:10.1016/j.engfracmech.2009.07.013

URL http://linkinghub.elsevier.com/retrieve/pii/S0013794409002380

[4] I. A. Ashcroft, D. J. Hughes, S. J. Shaw, Mode I fracture of epoxy bonded composite joints: 1. Quasi-static loading, International Journal of Adhesion and Adhesives 21 (2) (2001) 87-99. doi:10.1016/S0143-7496(00)00038-5

[5] B. F. Sørensen, Cohesive law and notch sensitivity of adhesive joints, Acta Materialia 50 (5) (2002) 1053-1061. doi:10.1016/S1359-6454(01)00404-9.

[6] H. Cui, S. Koussios, Y. Li, A. Beukers, Constitutive law of adhesive layer measured with mixed mode bending test, Engineering Fracture Mechanics 127 (2014) 235-251. doi:10.1016/j. engfracmech.2014.06.011.

URL http://dx.doi.org/10.1016/j.engfracmech.2014.06.011

[7] Q. D. Yang, M. D. Thouless, S. M. Ward, Elastic-plastic mode-II fracture of adhesive joints, International Journal of Solids and Structures 38 (18) (2001) 3251-3262. doi:10.1016/ S0020-7683(00) 00221-3.

[8] J. R. Reeder, J. R. Crews Jr., Mixed-mode bending Method for Delamination Testing, AIAA Journal 28 (7) (1990) 1270-1276. doi:10.2514/3.25204.

URL http://arc . aiaa.org/doi/10.2514/3.25204 
[9] M. D. Banea, L. F. M. D. A. Silva, R. D. S. G. Campilho, The Effect of Adhesive Thickness on the Mechanical Behavior of a Structural Polyurethane Adhesive, The Journal of Adhesion 91 (2015) 331-346. doi:10.1080/00218464.2014.903802.

[10] L. F. M. da Silva, F. A. C. R. G. de Magalhães, F. J. P. Chaves, M. F. S. F. de Moura, Mode II Fracture Toughness of a Brittle and a Ductile Adhesive as a Function of the Adhesive Thickness, The Journal of Adhesion 86 (2010) 891-905. doi:10.1080/00218464.2010.506155.

[11] G. Ji, Z. Ouyang, G. Li, S. Ibekwe, S.-S. Pang, Effects of adhesive thickness on global and local Mode-I interfacial fracture of bonded joints, International Journal of Solids and Structures 47 (2010) 2445-2458. doi:10.1016/j.ijsolstr.2010.05.006.

URL http://linkinghub.elsevier.com/retrieve/pii/S0020768310001769

[12] L. F. Kawashita, A. J. Kinloch, D. R. Moore, J. G. Williams, The influence of bond line thickness and peel arm thickness on adhesive fracture toughness of rubber toughened epoxyaluminium alloy laminates, Journal of Adhesion and Adhesives 28 (2008) 199-210. doi:10.1016/j.ijadhadh.2007.05.005

[13] S. Mostovoy, E. J. Ripling, C. F. Bersch, Fracture Toughness of Adhesive Joints Fracture, The Journal of Adhesion 3 (1971) 125-144. doi:10.1080/00218467108081159.

[14] M. D. Thouless, J. L. Adams, M. S. Kafkalidis, S. M. Ward, R. A. Dickie, G. L. Westerbeek, Determining the toughness of plastically deforming joints, Journal of Material Science 33 (1998) 189-197.

[15] C. Balzani, W. Wagner, D. Wilckens, R. Degenhardt, S. Büsing, H.-G. Reimerdes, Adhesive joints in composite laminates A combined numerical / experimental estimate of critical energy release rates, Journal of Adhesion and Adhesives 32 (2012) 23-38. doi:10.1016/j.ijadhadh. 2011.09 .002 .

[16] L. F. M. da Silva, V. H. C. Esteves, F. J. P. Chaves, Fracture toughness of a structural adhesive under mixed mode loadings, Materialwissenschaft und Werkstofftechnik 42 (5) (2011) 460-470. doi:10.1002/mawe.201100808.

[17] C. V. Katsiropoulos, A. N. Chamos, K. I. Tserpes, S. G. Pantelakis, Fracture toughness and shear behavior of composite bonded joints based on a novel aerospace adhesive, Composites 
Part B: Engineering 43 (2) (2012) 240-248. doi:10.1016/j.compositesb.2011.07.010.

URL http://linkinghub.elsevier.com/retrieve/pii/S1359836811003106

[18] S. Mostovoy, E. J. Ripling, Fracture Toughness of an Epoxy System, Journal of Applied Polymer Science 10 (1966) 1351-1371.

[19] V. Tvergaard, J. W. Hutchinson, On the toughness of ductile adhesive joints, Journal of the Mechanics and Physics of Solids 44 (5) (1996) 789-800. doi:10.1016/0022-5096(96)00011-7.

[20] G. Barenblatt, The formation of equilibrium cracks during brittle fracture. General ideas and hypotheses. Axially-symmetric cracks, Journal of Applied Mathematics and Mechanics 23 (3) (1959) 622-636. arXiv:0021-8928(59)90157-1, doi:10.1016/0021-8928(59)90157-1.

URL http://www . sciencedirect.com/science/article/pii/0021892859901571

[21] D. Dugdale, Yielding of steel sheets containing slits, Journal of the Mechanics and Physics of Solids 8 (2) (1960) 100-104. doi:10.1016/0022-5096(60)90013-2.

URL http://www.sciencedirect.com/science/article/pii/0022509660900132

[22] F. Kadioglu, R. D. Adams, Flexible adhesives for automotive application under impact loading, International Journal of Adhesion and Adhesives 56 (2015) 73-78. doi:10.1016/j.ijadhadh. 2014.08.001.

URL http://dx.doi.org/10.1016/j.ijadhadh.2014.08.001

[23] J. Casas-Rodriguez, I. Ashcroft, V. Silberschmidt, Damage evolution in adhesive joints subjected to impact fatigue, Journal of Sound and Vibration 308 (2007) 467-478. doi: $10.1016 / \mathrm{j} \cdot \mathrm{jsv} \cdot 2007.03 .088$ URL http://linkinghub.elsevier.com/retrieve/pii/S0022460X07002994

[24] W. Hufenbach, F. M. Ibraim, A. Langkamp, R. Böhm, A. Hornig, Charpy impact tests on composite structures - An experimental and numerical investigation, Composites Science and Technology 68 (12) (2008) 2391-2400. doi:10.1016/j.compscitech.2007.10.008.

URL http://linkinghub.elsevier.com/retrieve/pii/S0266353807004071

[25] H. Kolsky, An Investigation of the Mechanical Properties of Materials at very High Rates of Loading, Proceedings of the Physical Society.Section B 62 (11) (1949) 676-700.

URL http://stacks . iop. org/0370-1301/62/i=11/a=302 
[26] T. Yokoyama, Experimental determination of impact tensile properties of adhesive butt joints with the split Hopkinson bar, The Journal of Strain Analysis for Engineering Design 38 (3) (2003) 233-245. doi:10.1243/030932403765310563

URL http://journals.pepublishing.com/openurl.asp?genre=article $\{\&\}$ id=doi: $10.1243 / 030932403765310563$

[27] T. Yokoyama, K. Nakai, Determination of the impact tensile strength of structural adhesive butt joints with a modified split Hopkinson pressure bar, International Journal of Adhesion and Adhesives 56 (2015) 13-23. doi:10.1016/j.ijadhadh.2014.07.011.

URL http://dx.doi.org/10.1016/j.ijadhadh.2014.07.011

[28] J. J. M. Machado, E. A. S. Marques, L. F. M. da Silva, Adhesives and adhesive joints under impact loadings: An overview, The Journal of Adhesion 94 (6) (2018) 421-452. doi:10.1080/ 00218464.2017 .1282349 .

URL https://doi .org/10.1080/00218464.2017.1282349

[29] Y. Yamagata, X. Lu, Y. Sekiguchi, C. Sato, Experimental investigation of mode I fracture energy of adhesively bonded joints under impact loading conditions, Applied Adhesion Science 5 (7) (2017) 1-10. doi:10.1186/s40563-017-0087-7.

[30] J. Wiegand, A. Hornig, R. Gerlach, C. Neale, N. Petrinic, W. Hufenbach, An Experimental Method for Dynamic Delamination Analysis of Composite Materials by Impact Bending, Mechanics of Advanced Materials and Structures 22 (5) (2015) 413-421. doi:10.1080/15376494. 2012.736066 .

URL http://www.tandfonline.com/doi/abs/10.1080/15376494.2012.736066

[31] F. Delvare, J. L. Hanus, P. Bailly, A non-equilibrium approach to processing Hopkinson Bar bending test data: Application to quasi-brittle materials, International Journal of Impact Engineering 37 (12) (2010) 1170-1179. doi:10.1016/j.ijimpeng.2010.07.001

URL http://dx.doi.org/10.1016/j.ijimpeng.2010.07.001

[32] A. Needleman, A continuum Model for Void Nucleation by Inclusion Debonding, Journal of Applied Mechanics 54 (3) (1987) 525-531.

[33] T. Ungsuwarungsri, W. G. Knauss, The role of damage-softened material behavior in the 
fracture of composites and adhesives, International Journal of Fracture 35 (3) (1987) 221-241. doi:10.1007/BF00015590.

[34] V. Tvergaard, J. W. Hutchinson, The relation between crack growth resistance and fracture process parameters in elastic-plastic solids, Journal of the Mechanics and Physics of Solids 40 (6) (1992) 1377-1397. doi:10.1016/0022-5096(92)90020-3

[35] H. Cui, Simulation of ductile adhesive failure with experimentally determined cohesive law, Composites Part B 92 (2016) 193-201. doi:10.1016/j.compositesb.2016.02.018

URL http://dx.doi.org/10.1016/j.compositesb.2016.02.018

[36] M. May, O. Hesebeck, Assessment of experimental methods for calibrating rate-dependent cohesive zone models for predicting failure in adhesively bonded metallic structures, Engineering Failure Analysis 56 (2015) 441-453. doi:10.1016/j.engfailanal.2014.12.008

URL http://dx.doi.org/10.1016/j.engfailanal.2014.12.008

[37] G. Alfano, On the influence of the shape of the interface law on the application of cohesivezone models, Composites Science and Technology 66 (6) (2006) 723-730. doi:10.1016/j. compscitech.2004.12.024.

[38] A. Karac, B. Blackman, V. Cooper, A. Kinloch, S. Rodriguez Sanchez, W. Teo, A. Ivankovic, Modelling the fracture behaviour of adhesively-bonded joints as a function of test rate, Engineering Fracture Mechanics 78 (6) (2011) 973-989. doi:10.1016/j.engfracmech.2010.11. 014

URL http://www.sciencedirect.com/science/article/pii/S0013794410004893

[39] M. May, M. Nossek, N. Petrinic, S. Hiermaier, New rate dependent cohesive zone model for impact applications, in: 3rd ECCOMAS, 2011, pp. 137-144.

[40] M. May, Measuring the rate-dependent mode I fracture toughness of composites - A review Composites: Part A 81 (2016) 1-12. doi:10.1016/j.compositesa.2015.10.033

URL http://dx.doi.org/10.1016/j.compositesa.2015.10.033

[41] M. May, O. Hesebeck, S. Marzi, W. Böhme, J. Lienhard, S. Kilchert, M. Brede, S. Hiermaier, Rate dependent behavior of crash-optimized adhesives Experimental characterization, model development, and simulation, Engineering Fracture Mechanics 133 (2015) 112-137. doi:10. 
1016/j.engfracmech.2014.11.006

URL http://linkinghub .elsevier . com/retrieve/pii/S0013794414003804

[42] S. Marzi, O. Hesebeck, M. Brede, F. Kleiner, F. Ifam, A Rate-Dependent, Elasto-Plastic Cohesive Zone Mixed-Mode Model for Crash Analysis of Adhesively Bonded Joints Stress Unloading Path, in: 7th European LS-DYNA Conference, 2009.

[43] Aerospace - Anodic treatment of titanium and titanium alloys - Sulfuric acid process, International Organization for Standardization 1 (ISO 8080-1985 (E)).

[44] R. Gerlach, C. Kettenbeil, N. Petrinic, A new split Hopkinson tensile bar design, International Journal of Impact Engineering 50 (2012) 63-67. doi:10.1016/j.ijimpeng.2012.08.004

URL http://linkinghub.elsevier.com/retrieve/pii/S0734743X1200156X

[45] M. Lißner, E. Alabort, H. Cui, A. Pellegrino, N. Petrinic, On the rate dependent behaviour of epoxy adhesive joints: Experimental characterisation and modelling of mode I failure, Composite Structures 189 (2018) 286-303. doi:10.1016/j.compstruct.2018.01.019.

URL https://doi.org/10.1016/j.compstruct.2018.01.019

[46] M. C. Boyce, D. M. Parks, A. S. Argon, Large inelastic deformation of glassy polymers. part I: rate dependent constitutive model, Mechanics of Materials 7 (1) (1988) 15-33. doi:10.1016/ 0167-6636(88)90003-8

[47] D. Alvarez Feito, Fracture Mechanics of Carbon Fibre Reinforced Plastics to Ti-alloy Adhesive Joints, Ph.D. thesis, Imperial College London (2012). 
a) Mode I specimen
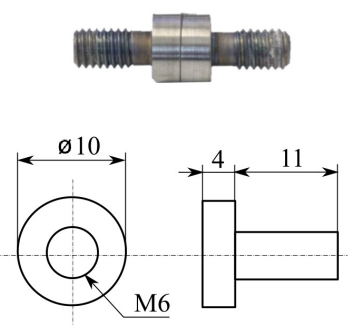

b) Mode II specimen
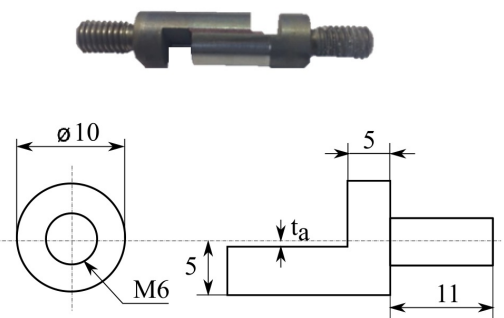

c) Mixed-Mode specimen
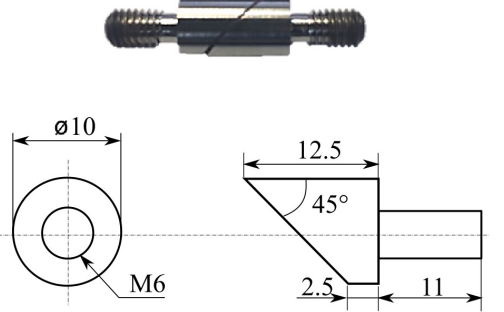

Figure 1: Overview of the specimen geometries for the loading modes: mode I, mode II and mixed-mode.

a) Bonding fixture

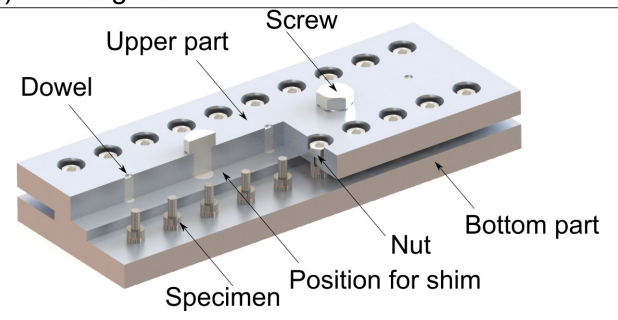

b) Specimen qualification

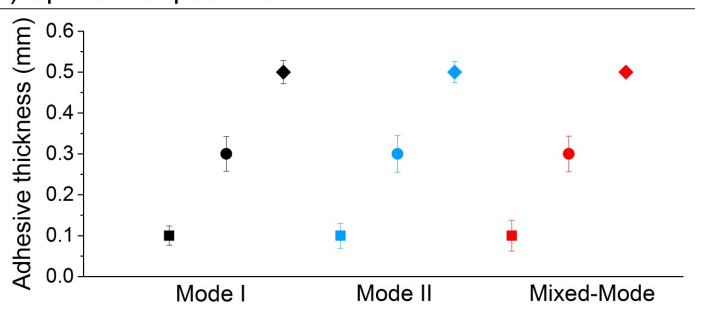

Figure 2: Schematic representation of (a) bonding fixture and (b) bondline measurements. 

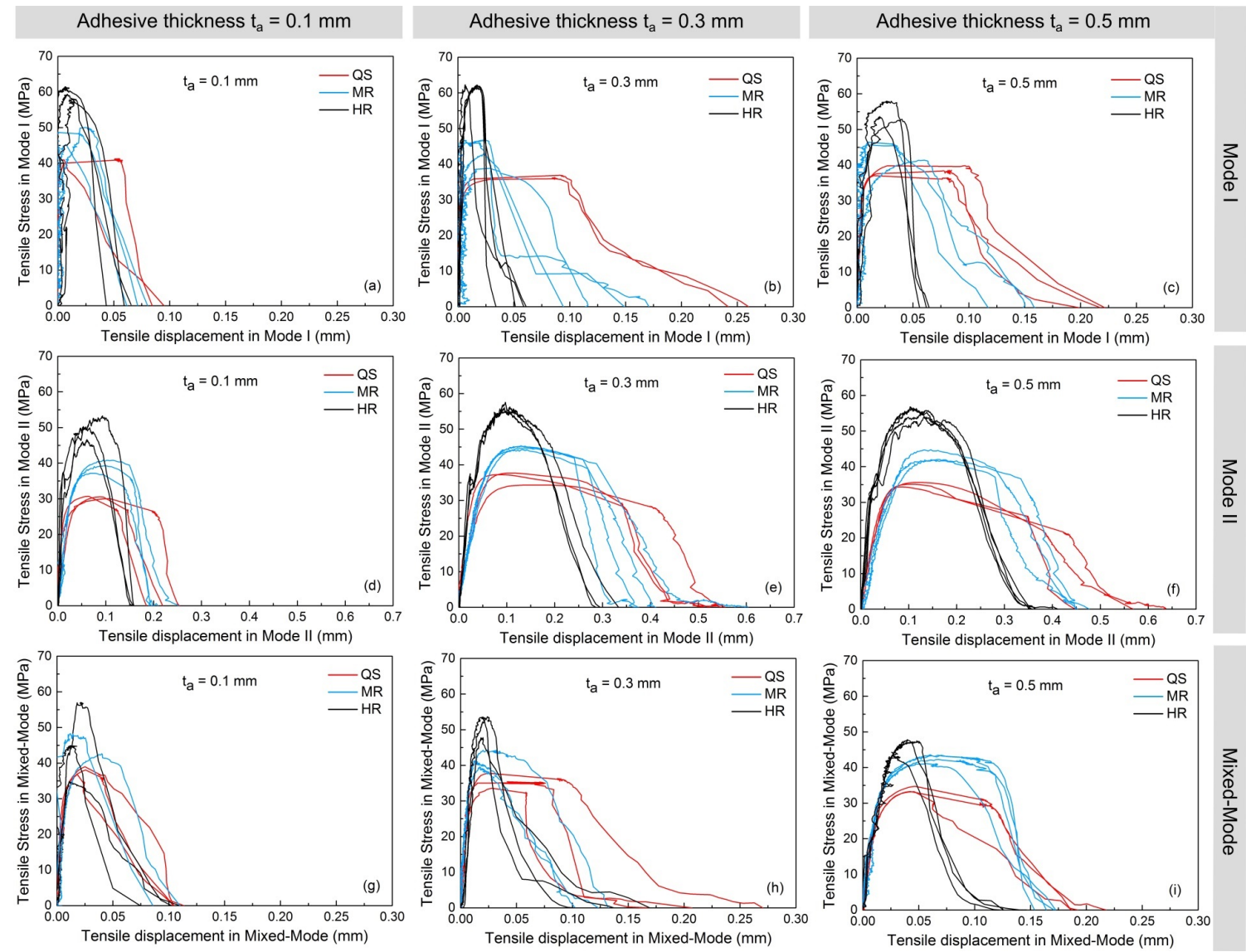

Figure 3: Results of the rate and thickness dependent experiments for mode I with the thicknesses (a) $t_{\mathrm{a}}=0.1 \mathrm{~mm}$, (b) $t_{\mathrm{a}}=0.3 \mathrm{~mm}$ and (c) $t_{\mathrm{a}}=0.5 \mathrm{~mm}$, for mode II with the adhesive layer thickness of (d) $t_{\mathrm{a}}=0.1 \mathrm{~mm},(\mathrm{e}) t_{\mathrm{a}}=0.3$ $\mathrm{mm}$ and (f) $t_{\mathrm{a}}=0.5 \mathrm{~mm}$ and for mixed-mode whith the bondline thickness $(\mathrm{g}) t_{\mathrm{a}}=0.1 \mathrm{~mm},(\mathrm{~h}) t_{\mathrm{a}}=0.3 \mathrm{~mm}$ and (i) $t_{\mathrm{a}}=0.5 \mathrm{~mm}$. 

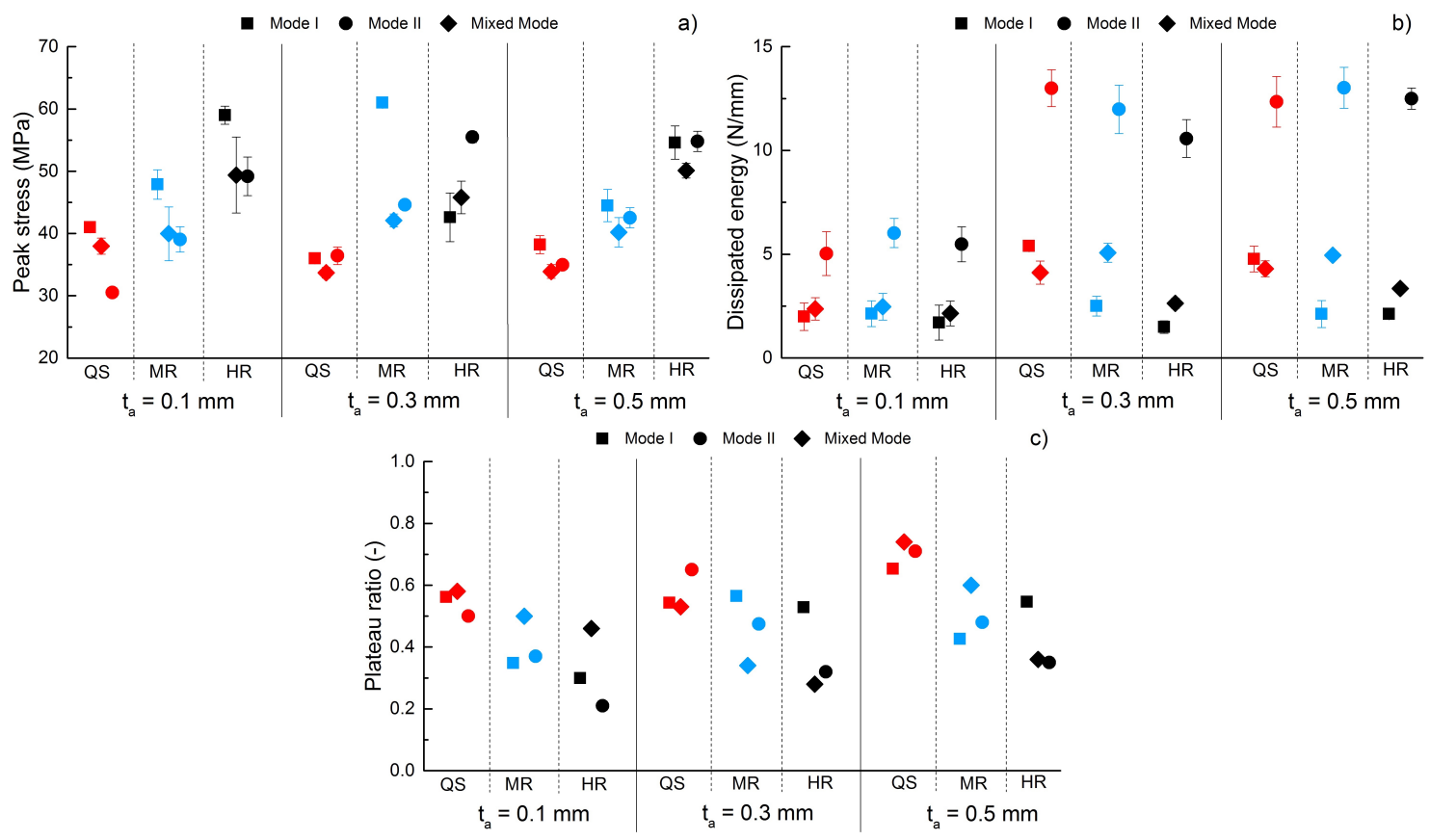

Figure 4: Influence of the adhesive thickness, loading rate and loading mode on (a) the peak stress, (b) the dissipated energy and (c) the plateau ratio.

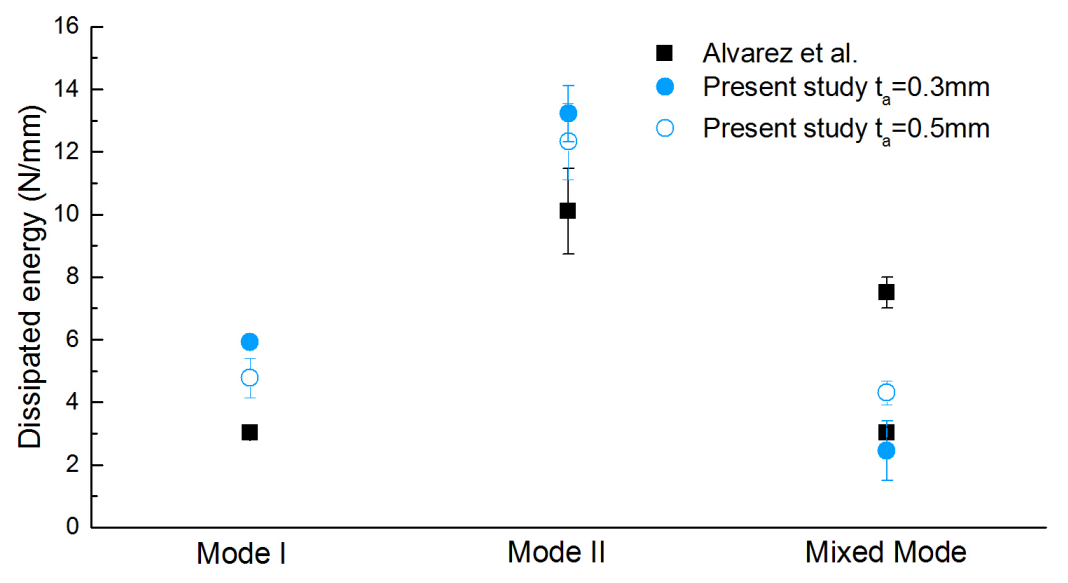

Figure 5: Comparison of the obtained dissipated energy for mode I, mode II and mixed-mode for the film adhesive AF 163-2OST. Blue indicates current study while black shows results measured by Alvarez et. al. [47. 


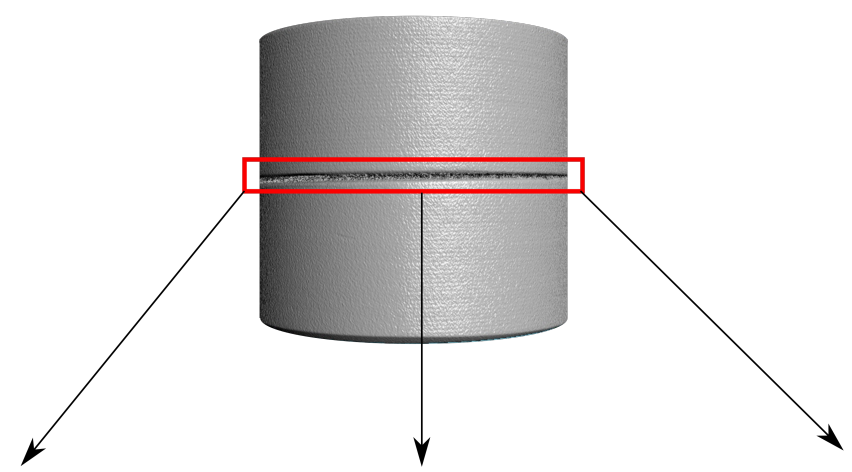

$\mathrm{t}_{\mathrm{a}}=0.1 \mathrm{~mm}$
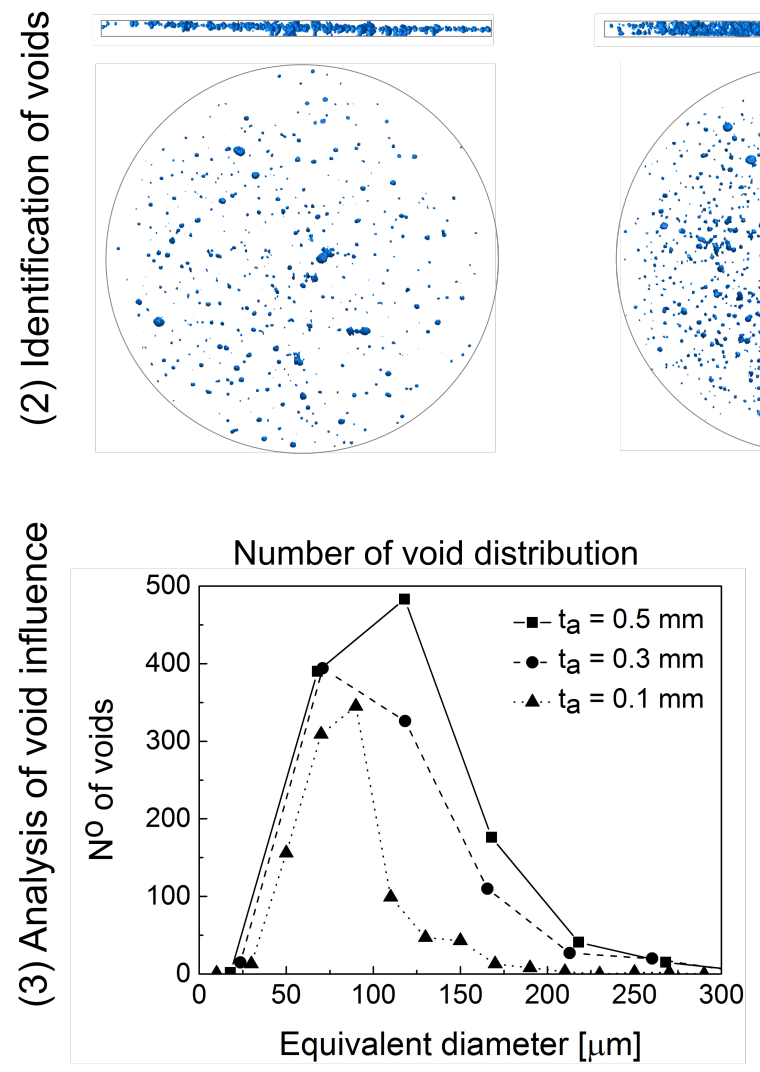

$\mathrm{t}_{\mathrm{a}}=0.3 \mathrm{~mm}$

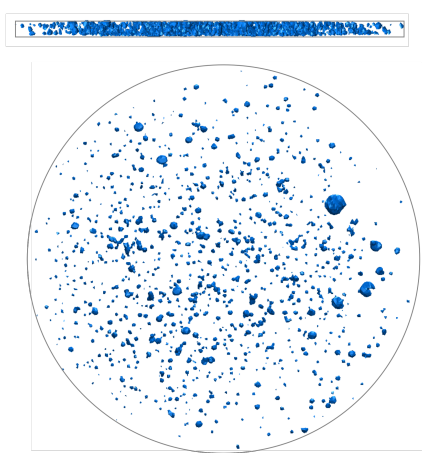

$\mathrm{t}_{\mathrm{a}}=0.5 \mathrm{~mm}$
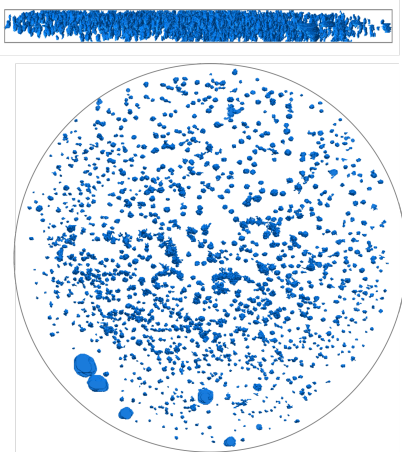

Void volume fraction

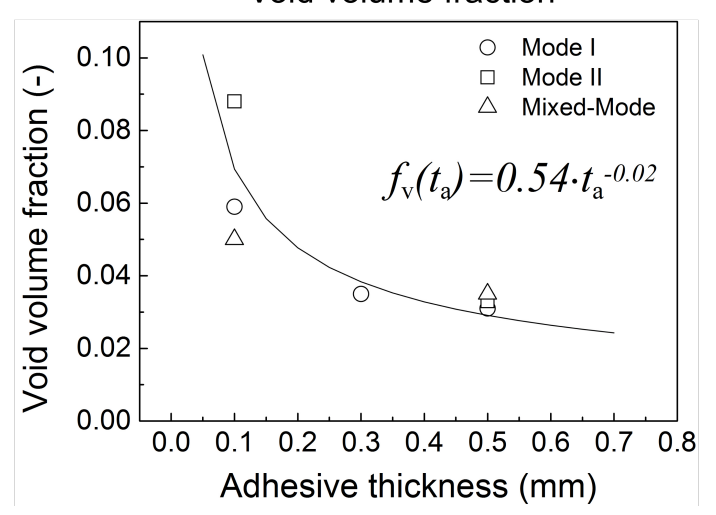

Figure 6: Results of computer tomography X-ray scans for representing the void distribution of the investigated bondline thicknesses $t_{\mathrm{a}}=0.1,0.3$ and $0.5 \mathrm{~mm}$, the number of voids over the equivalent void diameter and the void volume fraction. 


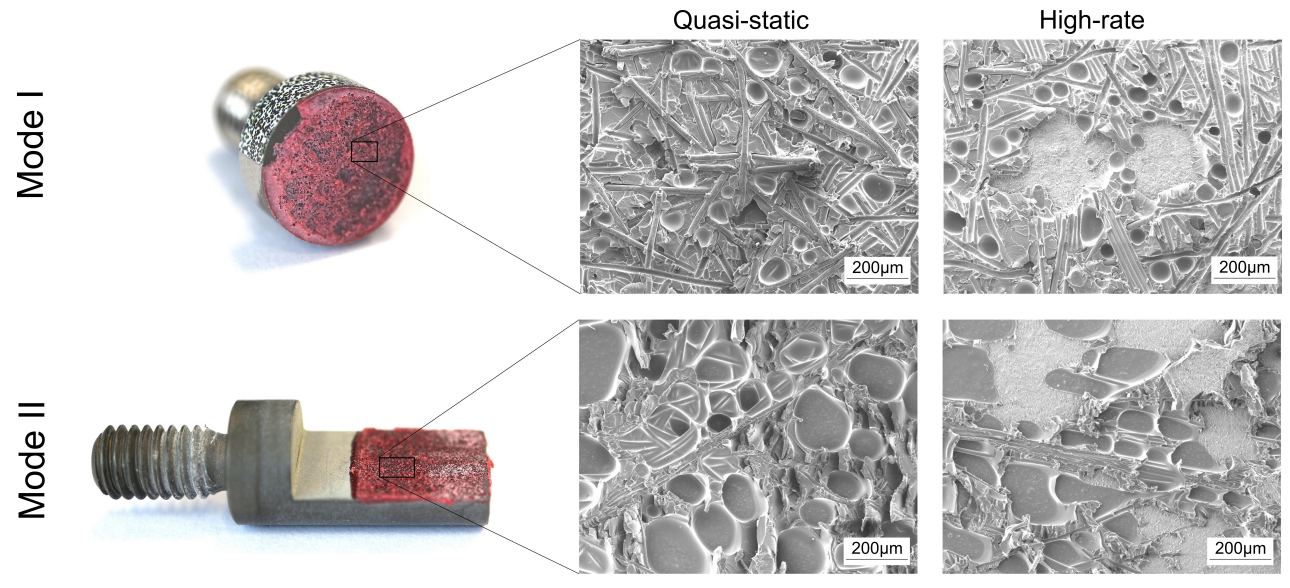

Figure 7: Representation of fractured mode I and II samples for an adhesive thickness of $t_{\mathrm{a}}=0.1 \mathrm{~mm}$ tested under quasi-static (QS) and high-rate (HR) loading. 


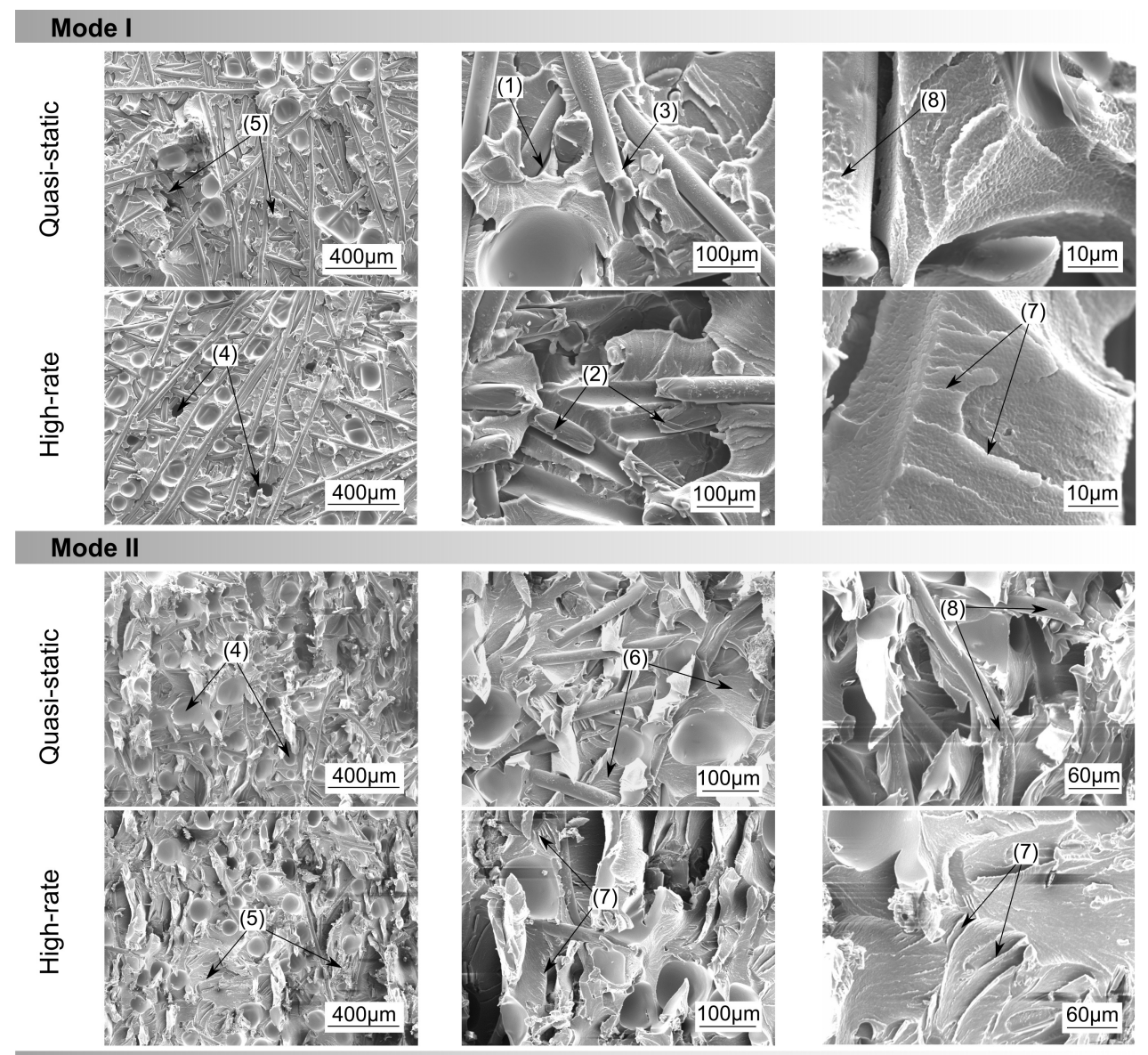

\section{Mixed Mode}
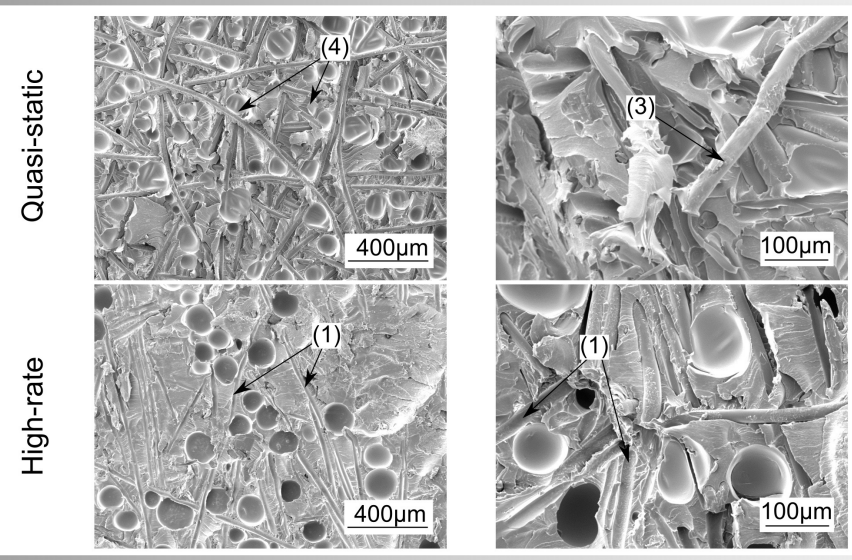

\section{Legend}

(1) Fibre debonding from matrix

(3) Fibre pull-out

(5) Matrix failure

(2) Fibre fracture

(4) Void

(6) Hackles

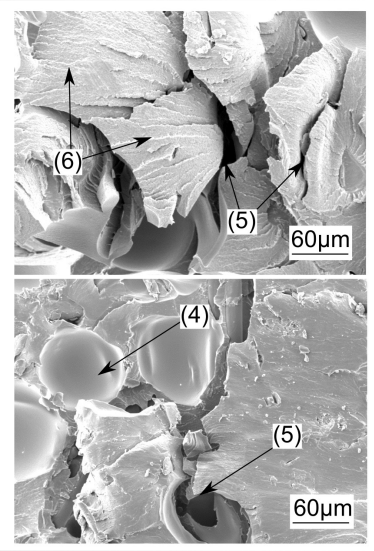

(7) Cusps

(8) Traces of matrix rupture

Figure 8: Fractured SEM micrographs showing detailed features of failure of the investigated film adhesive when tested under quasi-static and high-rate loading for an adhesive thickness of $t_{\mathrm{a}}=0.5 \mathrm{~mm}$. 

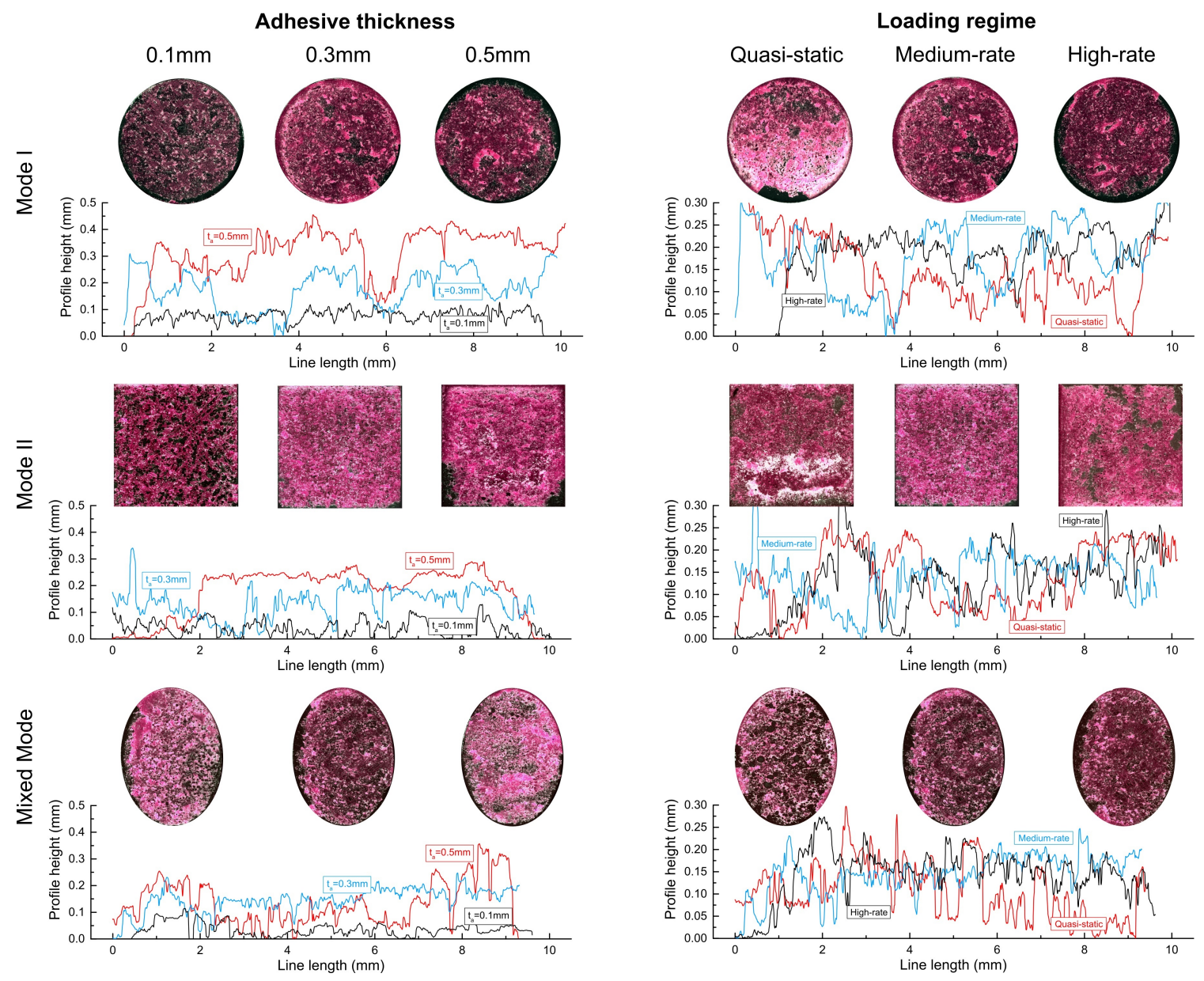

Figure 9: Optical micrographs of the adhesives after fracture for different adhesive thicknesses and different loading regimes. 
a) Traction separation law

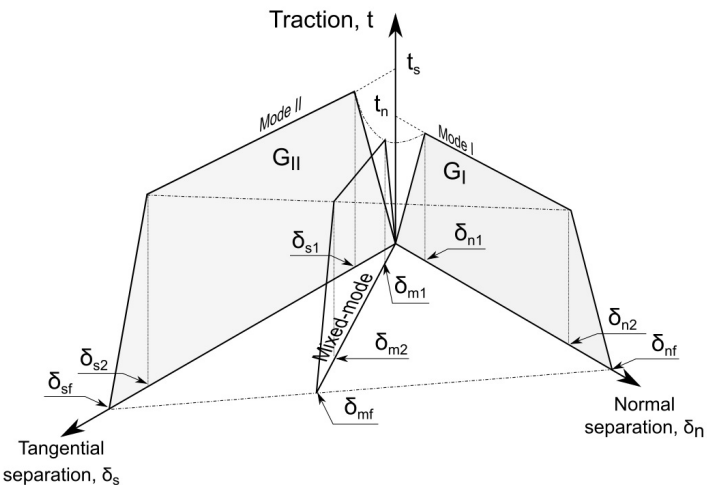

b) Used terminology

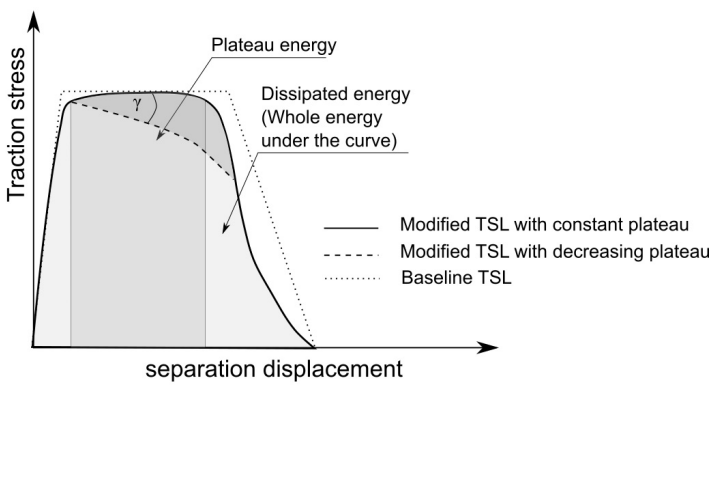

Figure 10: Representation of (a) a typical trilinear traction-separation law and (b) the used terminology for the different energies used in the mathematical model. 


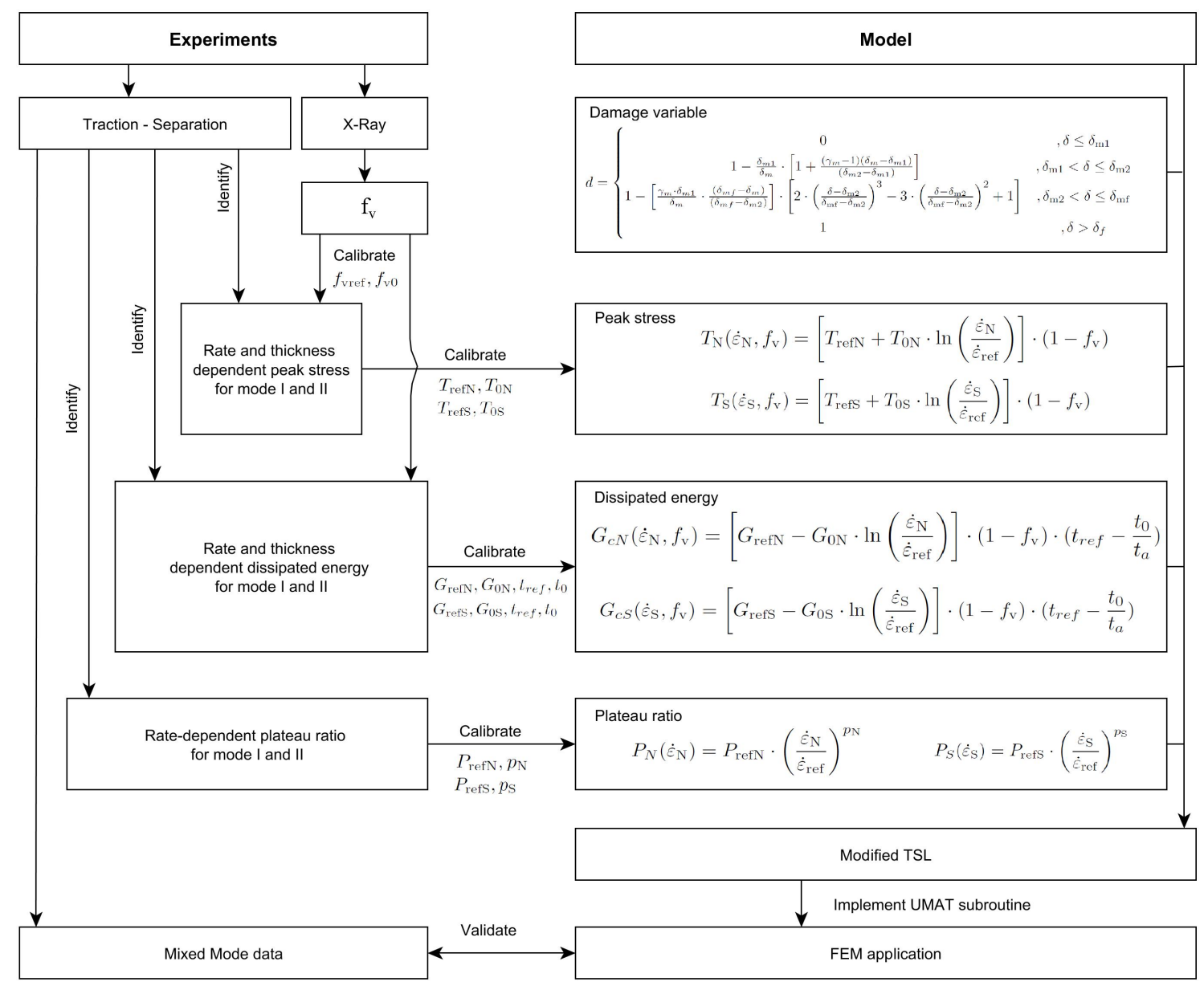

Material dependent modelling parameters

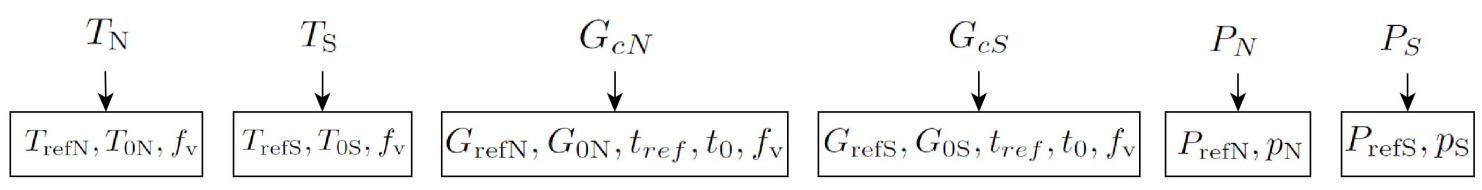

Figure 11: Parameter optimisation process for the mathematical model representation. 

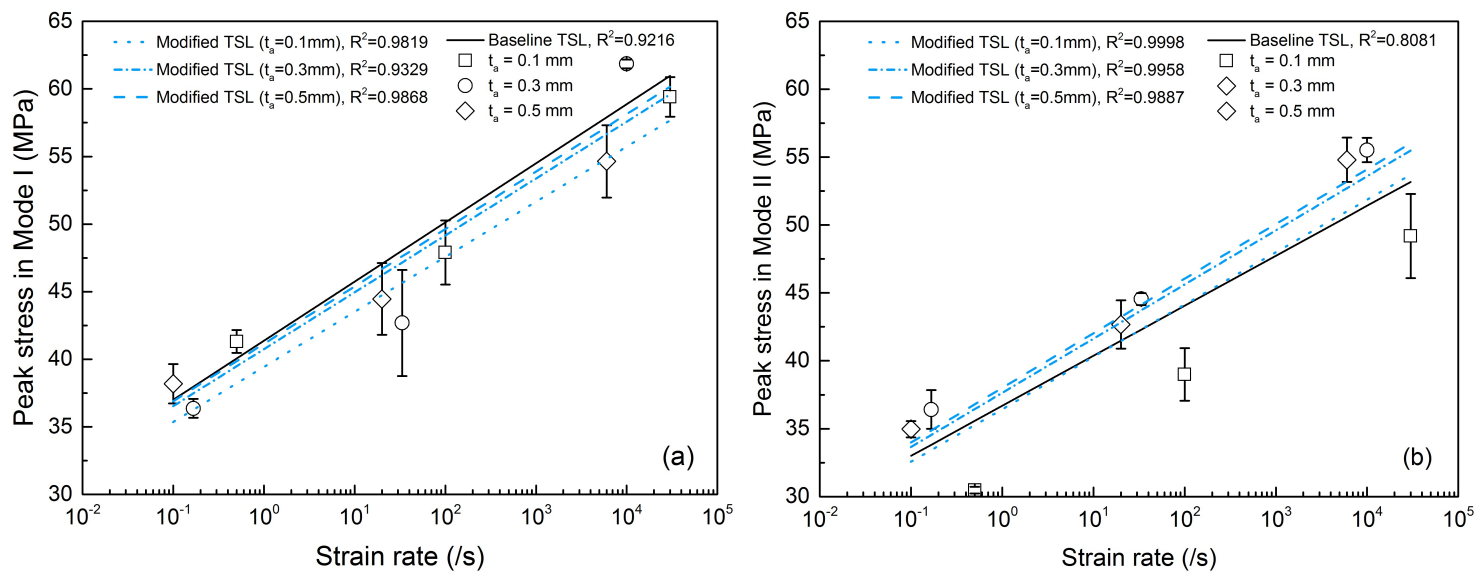

Figure 12: Comparison between modelled results and experimental data for the rate-dependent behaviour of the peak stress for (a) mode I and (b) mode II.
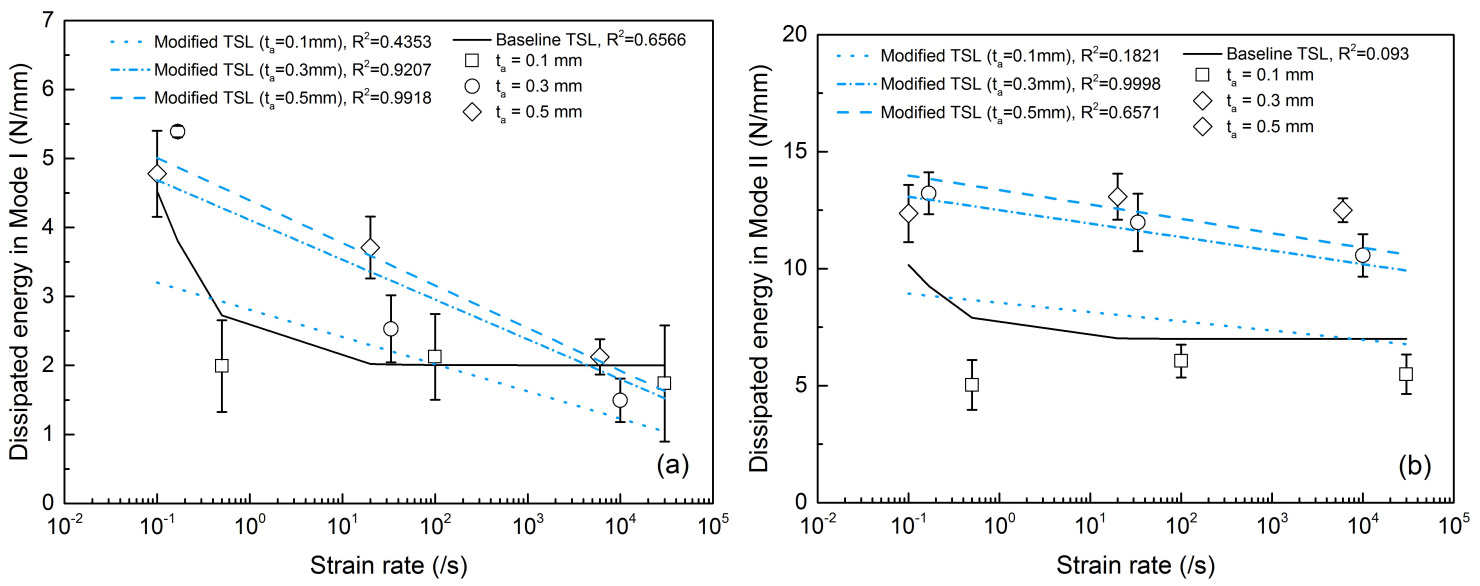

Figure 13: Comparison between modelled results and experimental data for the rate-dependent behaviour of the dissipated energy for (a) mode I and (b) mode II. 

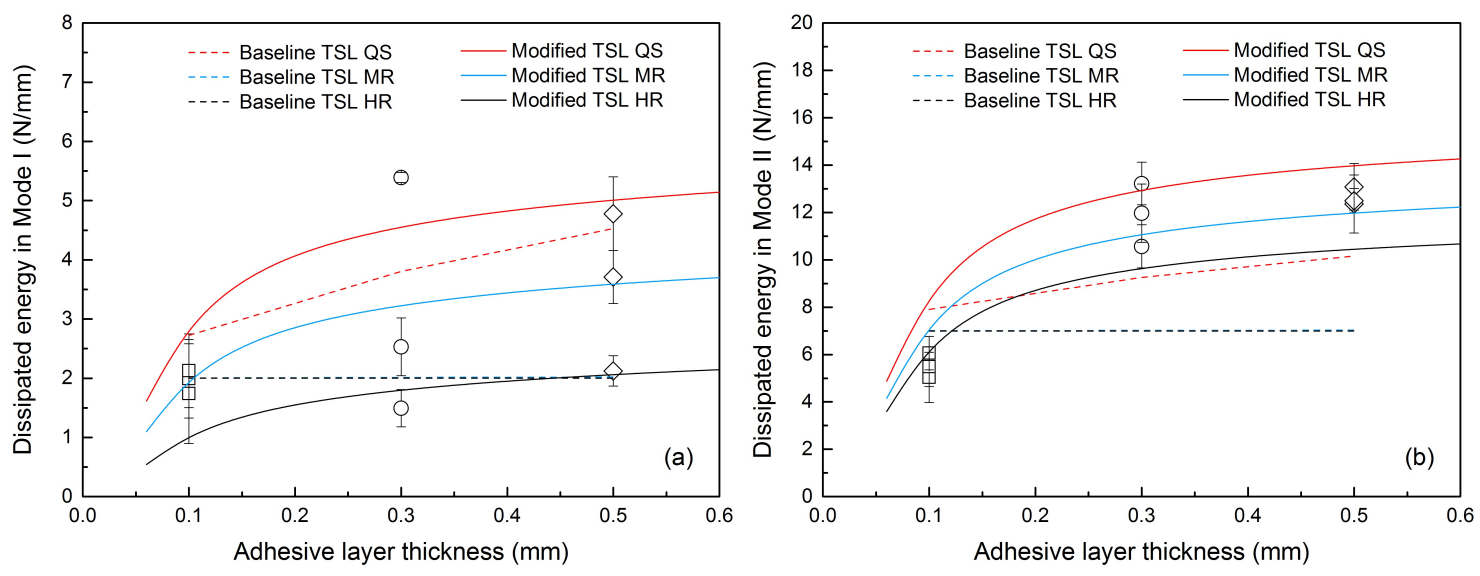

Figure 14: Comparison between modelled results and experimental data for the thickness-dependent behaviour of the dissipated energy for (a) mode I and (b) mode II.
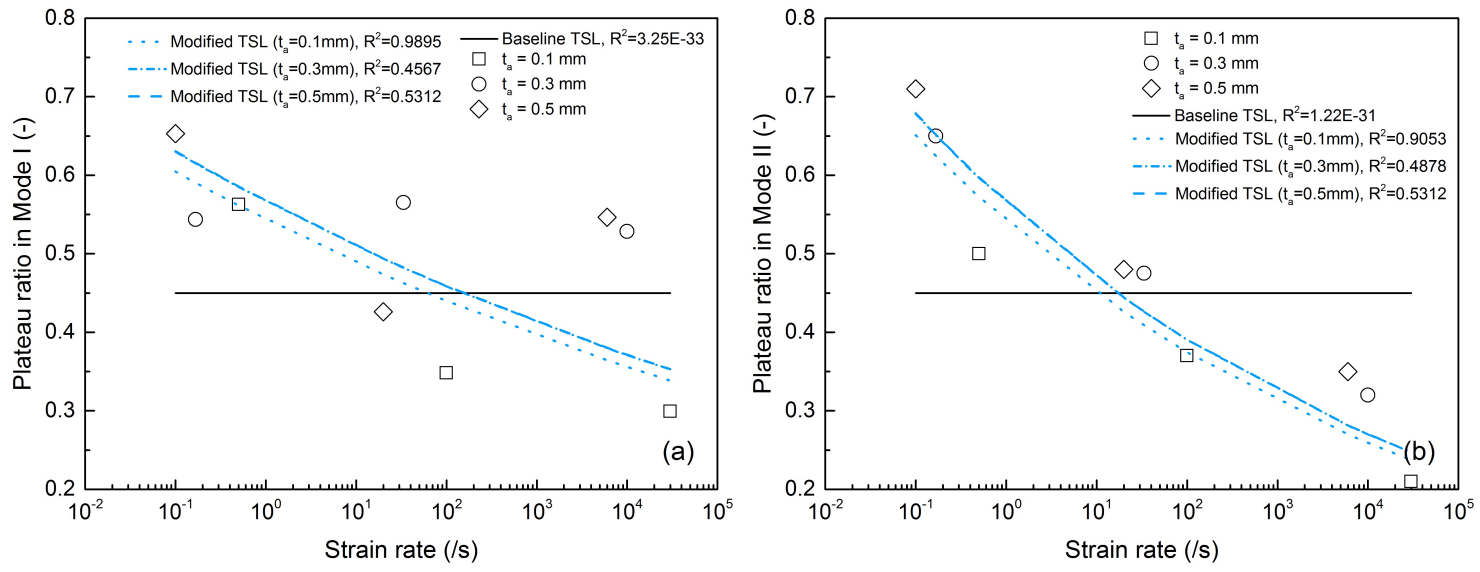

Figure 15: Comparison between modelled results and experimental data for the rate-dependent behaviour of the plateau ratio for (a) mode I and (b) mode II. 

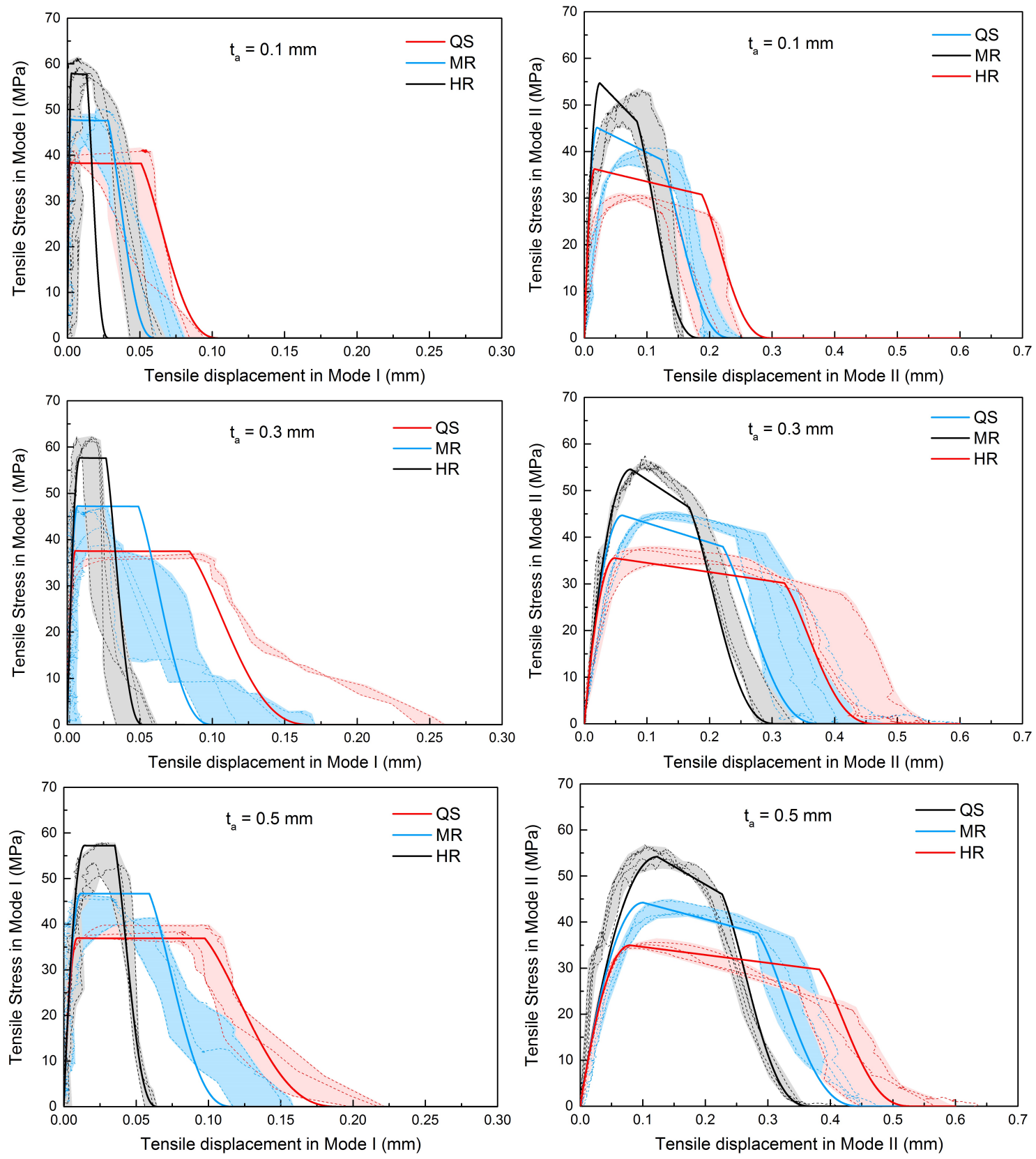

Figure 16: Results of the TSL model (solid lines) and experiments (shaded area) for titanium-titanium adhesive joints characterised under quasi-static, medium-rate and high-rate loadings. Results are shown for; (a) $t_{\mathrm{a}}=0.1 \mathrm{~mm}$, (b) $t_{\mathrm{a}}=0.3 \mathrm{~mm}$, and (c) $t_{\mathrm{a}}=0.5 \mathrm{~mm}$ in mode I; and (d) $t_{\mathrm{a}}=0.1 \mathrm{~mm},(\mathrm{e}) t_{\mathrm{a}}=0.3 \mathrm{~mm}$, and $t_{\mathrm{a}}=0.5$ mm in mode II. 


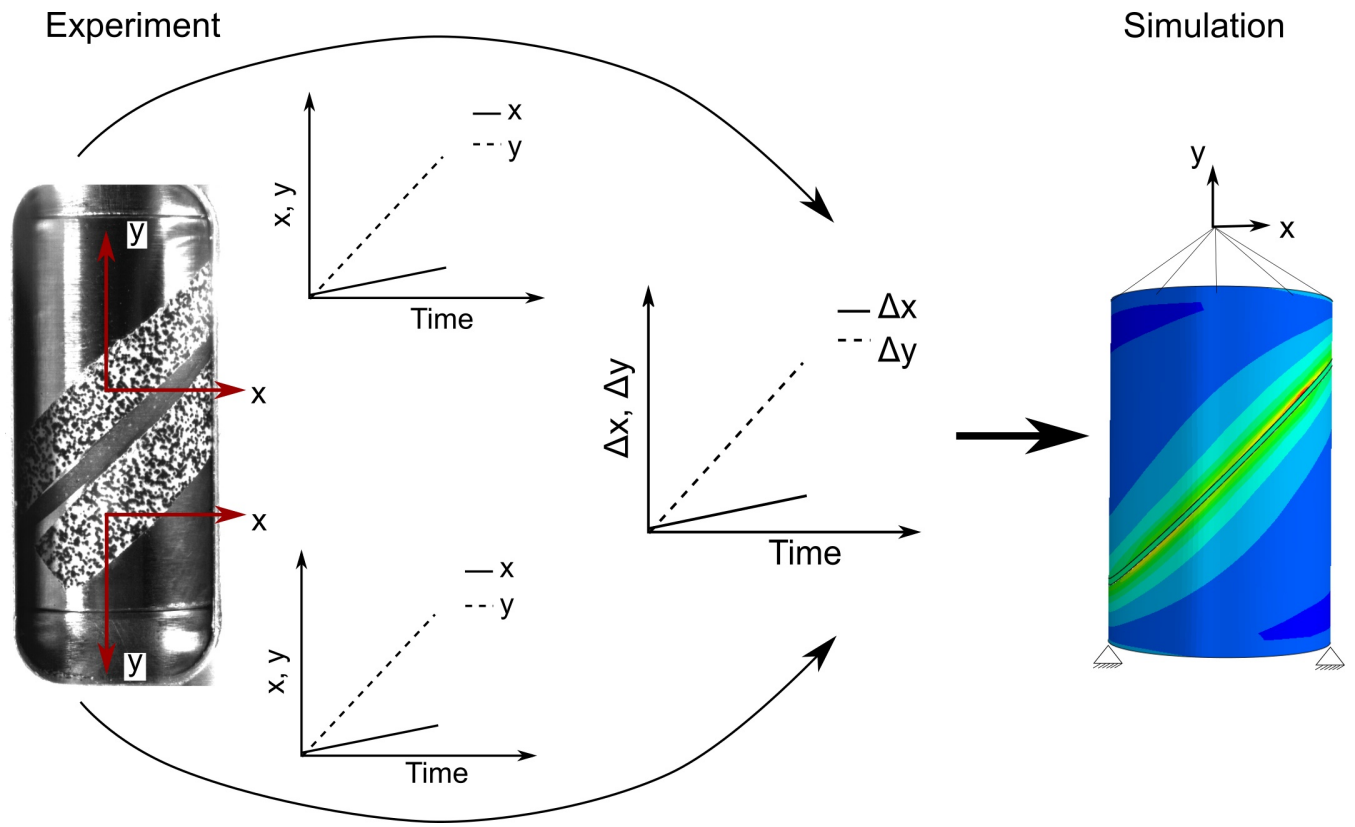

Figure 17: Determination of the experimental boundary conditions for the simulation of mixed-mode experiments. 


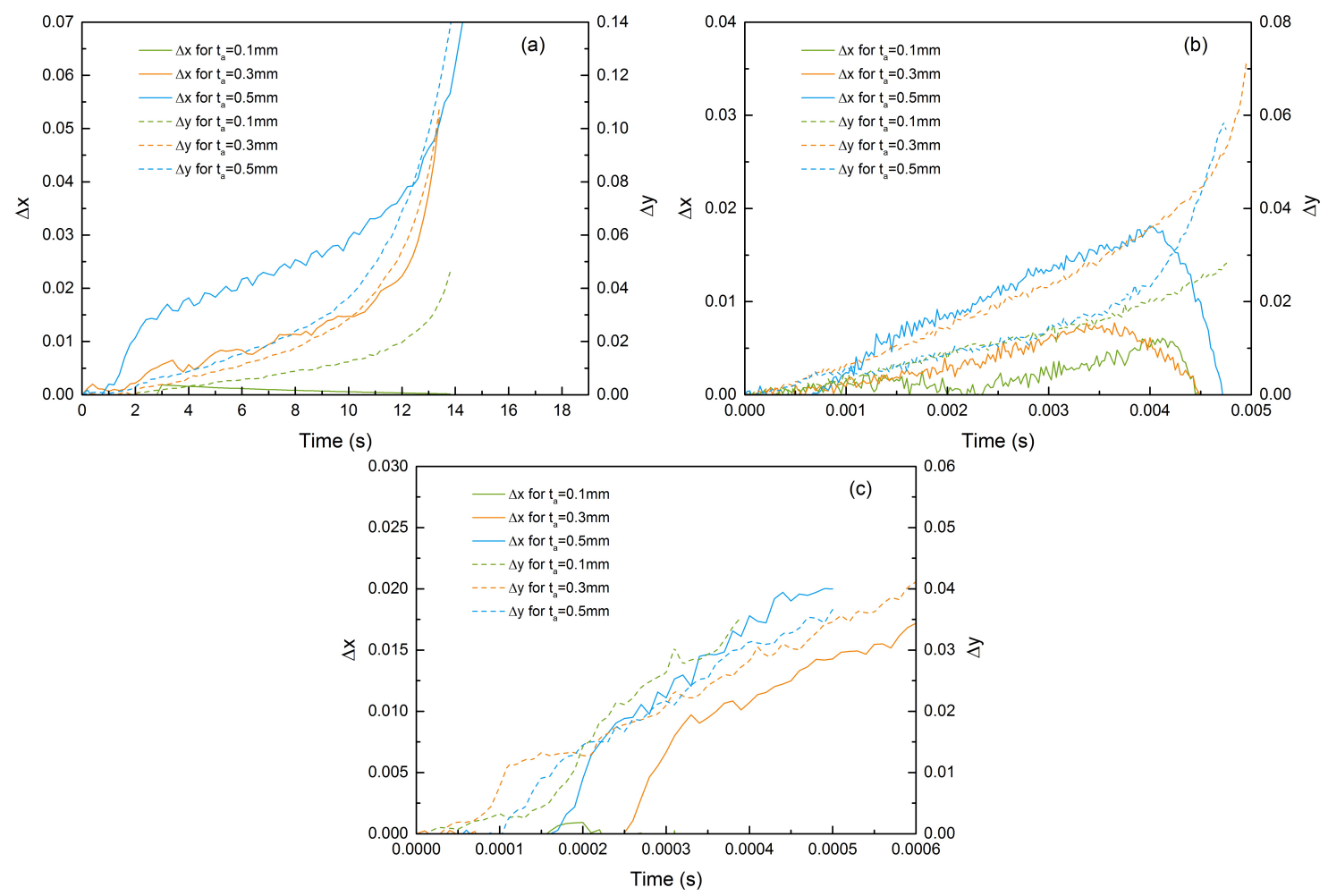

Figure 18: Experimentally obtained relative displacements for a) quasi-static, b) medium-rate and c) high-rate loading regimes for three investigated adhesive thicknesses. 

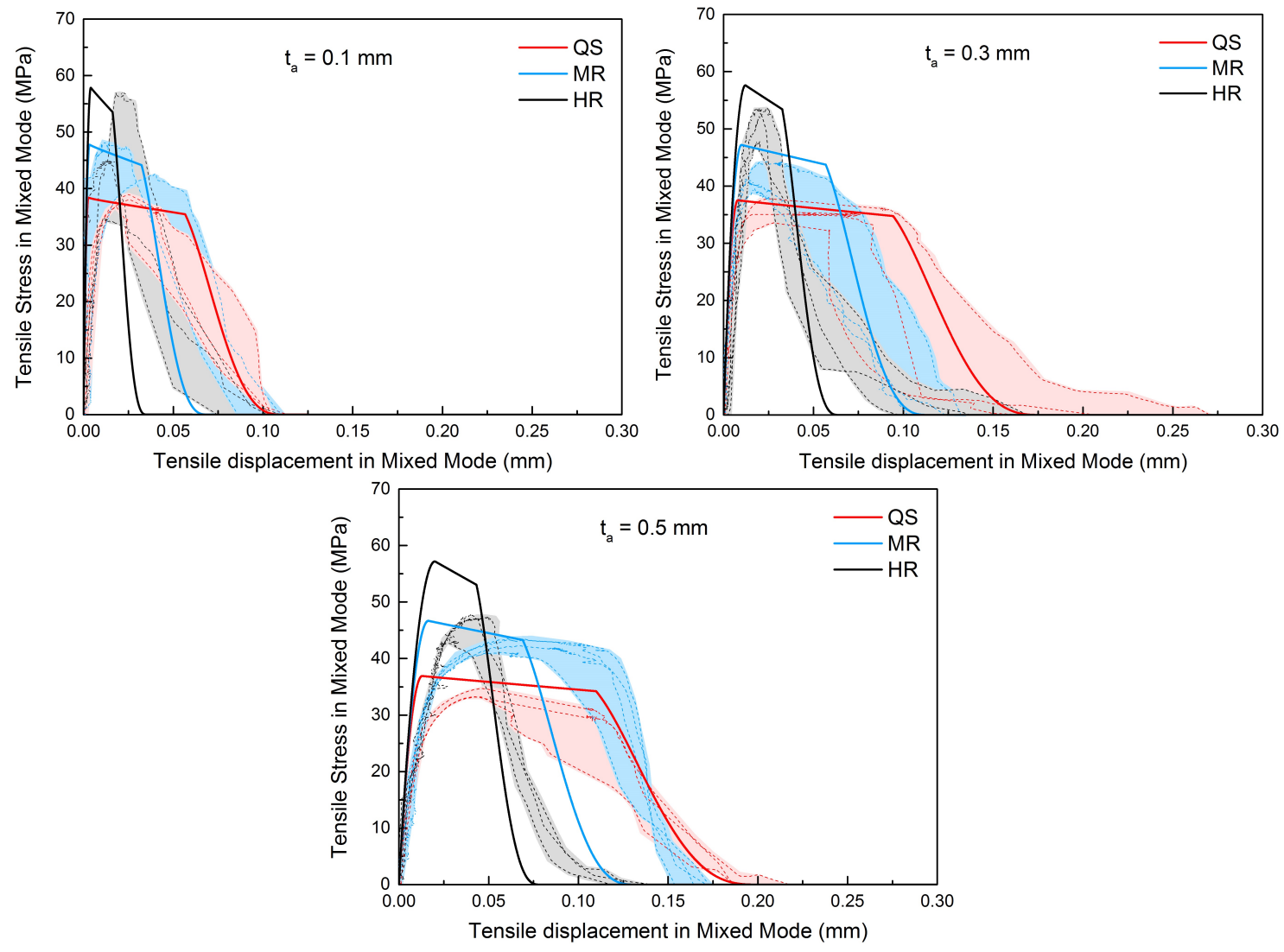

Figure 19: Validation of the model (solid line) against the experimental results (shaded area) for a thickness of: (a) $t_{\mathrm{a}}=0.1 \mathrm{~mm}$, (b) $t_{\mathrm{a}}=0.3 \mathrm{~mm}$ and (c) $t_{\mathrm{a}}=0.5 \mathrm{~mm}$ in mixed-mode. 


\title{
Experimental characterisation and
} numerical modelling of the influence of bondline thickness, loading rate, and deformation mode on the response of ductile adhesive interfaces

\author{
Lissner, Maria
}

Elsevier

Lissner M, Alabort E, Cui H, et al., (2019) Experimental characterisation and numerical modelling of the influence of bondline thickness, loading rate, and deformation mode on the response of ductile adhesive interfaces. Journal of the Mechanics and Physics of Solids, Volume 130, September 2019, pp. 349-369

https://doi.org/10.1016/j.jmps.2019.06.011

Downloaded from Cranfield Library Services E-Repository 